\title{
TWENTY-FIVE YEARS OF HAND SURGERY
}

\author{
Personal Reflections
}

\author{
R. Guy Pulvertaft, Derby, England
}

"How much better is it to get wisdom than gold! and to get understanding rather to be chosen than silver!"

Proverbs, 16, 16.

Surgery of the hand has made impressive progress during the past twenty-five years. Throughout the world, increasing attention has been given to hands disabled by congenital malformation, injury or disease. Intimate studies of the anatomy, knowledge gained from research and improved surgical techniques have combined to advance this work. With any surgical discipline there is the need to go forward, but it is wise also to look back so that mistakes are not repeated and to ensure that we hold fast to that which is shown to be sound. I propose to look over my shoulder at some of the problems I have encountered over the past quarter of a century, and endeavour to see where truth and error lie.

\section{CONGENITAL MALFORMATION}

\section{CLUB HAND}

Radial aplasia has been described many times and particularly so during the early days of orthopaedic surgery (Kato 1924). The whole limb may be affected, but it is with the elbow, forearm and hand that we are chiefly concerned. The extrinsic and intrinsic muscles of the digits are affected in varying degrees of severity. The nerves and vessels are anomalous, particularly the median and radial nerves. The thumb is rarely normal; anomalies vary from minor defects to absence. The ring and little fingers are usually normal, but in most cases there is restricted movement of the index and middle fingers and occasionally there are bizarre deformities of all digits. There is a natural tendency to develop an ulnar dominant grip and the surgeon should observe the action of the hand carefully before advising transfer of the index finger to the thumb position.

The skeletal malformation falls into three main patterns (Fig. 1): 1) complete absence of the radius; 2) absence of the distal half of the radius; and 3) complete but short radius.

The ulna is usually but not invariably curved. A curvature may develop or increase if corrective splintage is not commenced in infancy. The scaphoid and trapezium are usually absent. The lower ulnar epiphysis fuses at an early age, ten to fourteen years (normal sixteen to eighteen years), and the mature forearm attains only half to three-quarters of the normal length (Heikel 1959) (Fig. 2).

The final function of the limb and of the hand in particular is the main consideration when deciding upon treatment, but the deformity is so ugly that the appearance should be improved if it is possible to do so without diminishing the function. It is well to remember that corrective treatment is indicated only when there is an adequate controlled elbow range, for radial deviation of the wrist is advantageous when the elbow cannot be flexed. In some children the elbow range improves with growth, and it is reasonable to anticipate this possibility and use corrective splintage of the wrist from infancy. Nothing is lost by doing so and permanent correction may be achieved later if it is justifiable.

Many forms of operative treatment (Fig. 3) have been practised, which no doubt indicates the frustration that has been experienced: 1) osteotomy of the ulnar shaft (Hoffa 1890); 2) centralisation of the carpus upon the ulna (Sayre 1894);3) splitting of the lower end of 

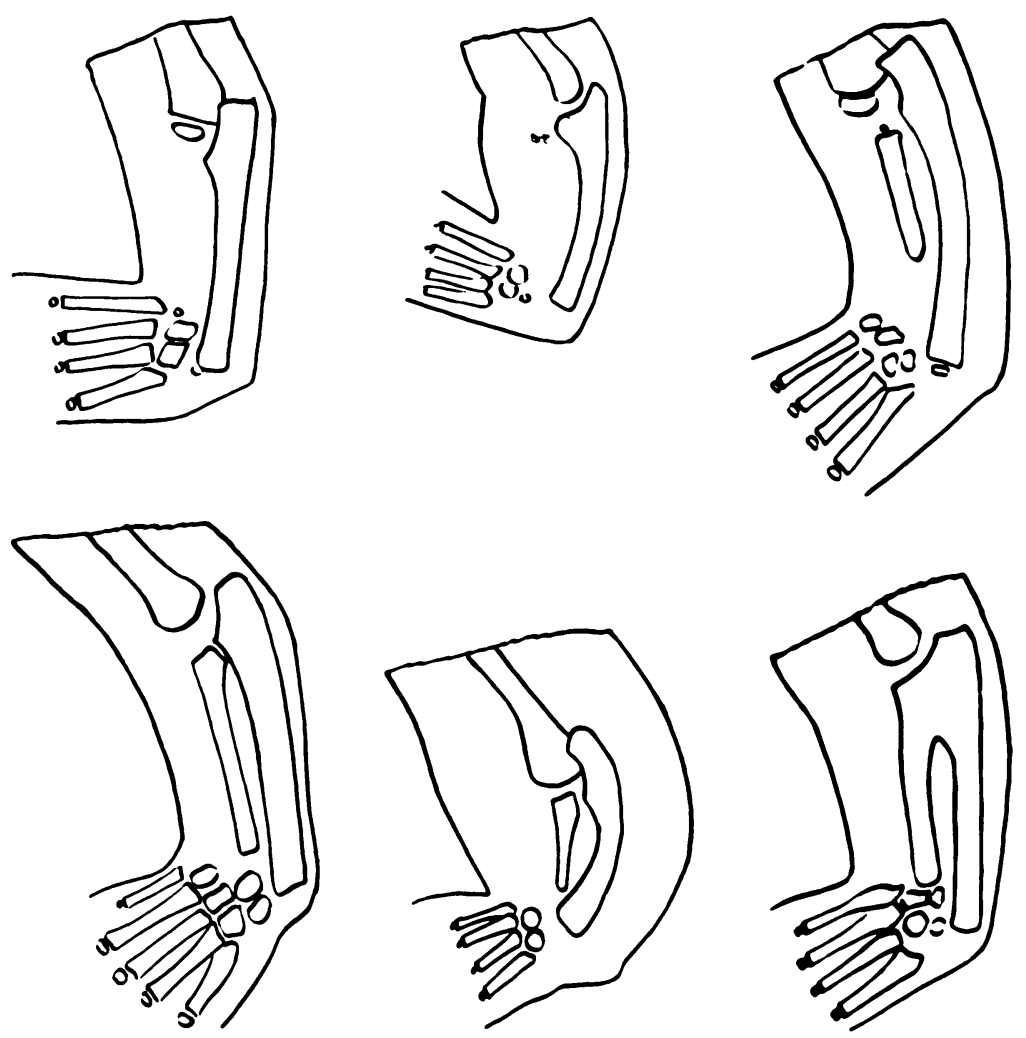

FIG. 1

Club hand. Typical patterns of deformity traced from radiographs.

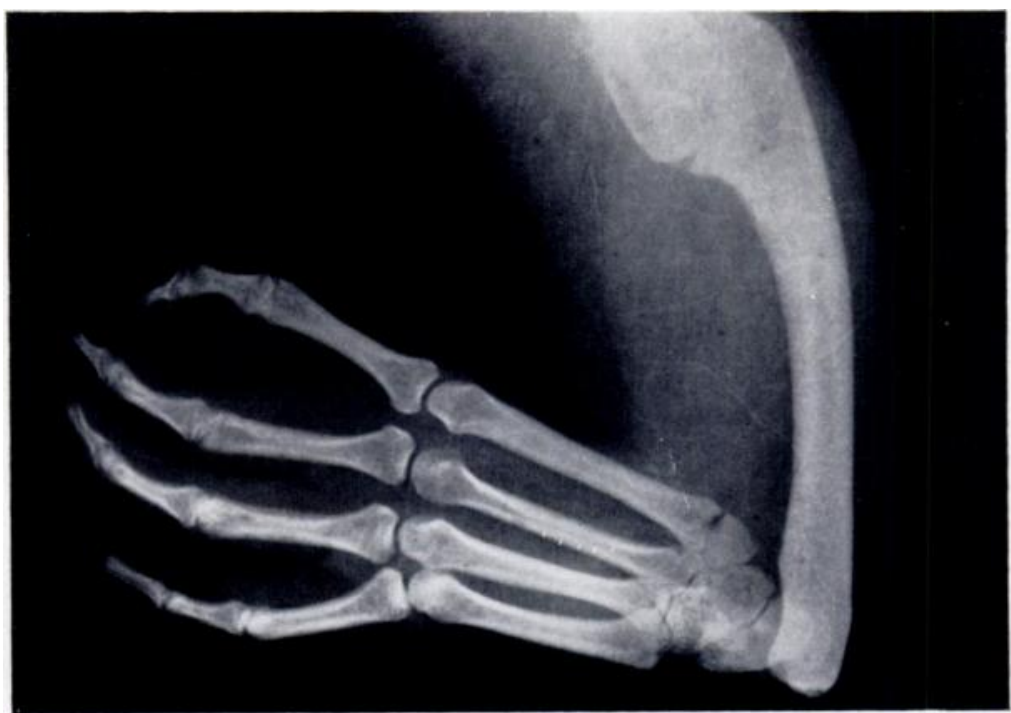

Fig. 2

Untreated club hand in a woman aged 23 years, showing arrested development of the ulna. 
the ulna (Bardenheuer 1894); 4) osteotomy of the lower end of the ulna (Romano 1894); 5) tibial bone graft (Albee 1919, 1928); 6) ulnar bone graft (Ryerson 1924); 7) fibular epiphysial bone graft (Starr 1945); 8) detachment of the lower end of the ulna from its periosteal sleeve and its displacement to the radial side of the carpus (Define 1963).

A definition of the ideal treatment is correction and freedom from splintage at an early age to enable the child to develop a functional pattern. The correction should be complete and permanent without disturbance of growth and without loss of wrist movement. Unfortunately, this ideal cannot be achieved and all methods so far described fall short in one way or another.

A static bone graft is of some value for the older patient, but the most attractive proposition is the formation of a radius capable of growing in pace with the ulna. Unfortunately,

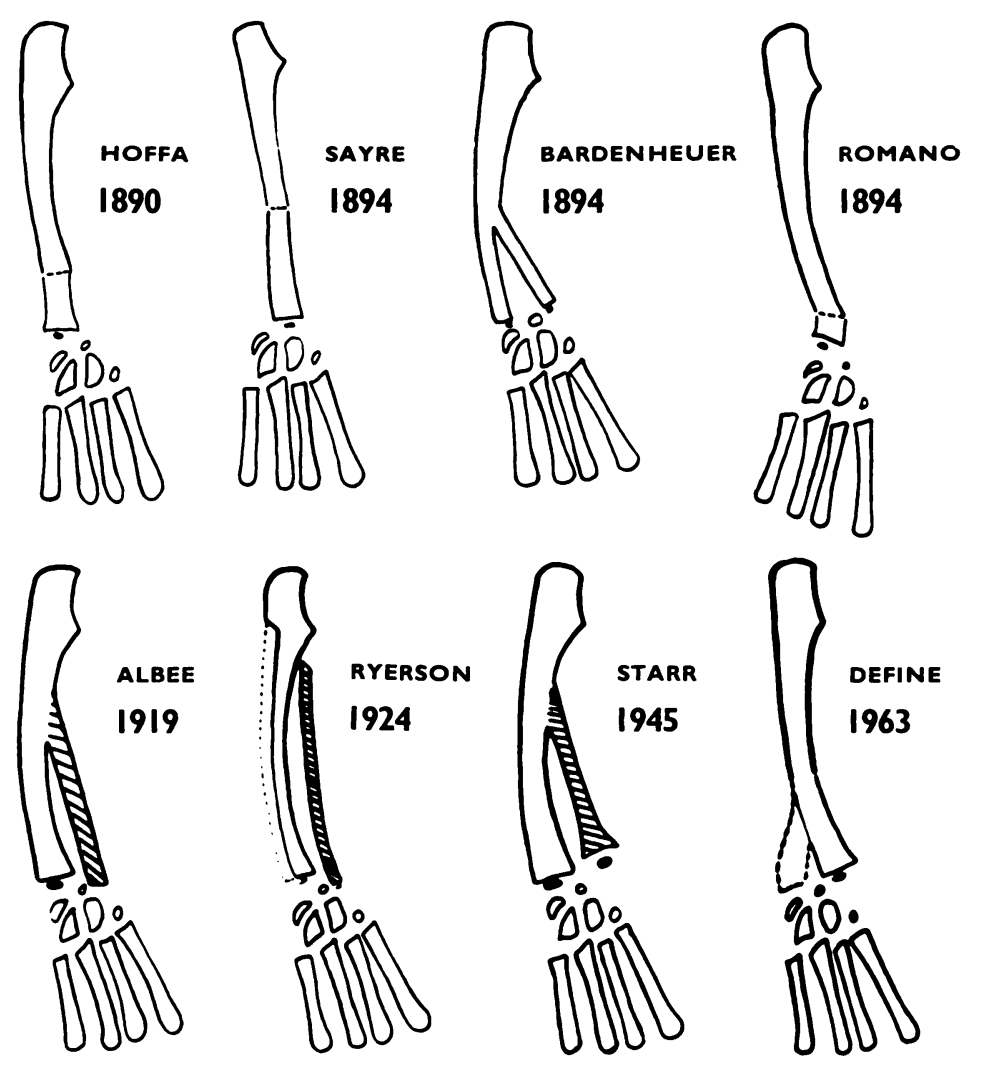

Fig. 3

Methods of surgical treatment for club hand.

a transplanted epiphysis will not continue to grow and the initial promise of success is not sustained (Figs. 4 to 6). Perhaps in the future a method of transplantation will be devised which does not disturb the growth potential.

Centralisation of the carpus upon the ulna as first performed by Sayre of New York in 1894 has attracted attention in recent years and is probably the most suitable treatment for the average case. Opinions differ as to the most suitable age to perform the centralisation and I can only speak from my own experience. The age of four years has been chosen but the preparatory treatment starts during infancy. The placing of the ulnar head into a carpal recess can be performed without risk to the ulnar growth plate only if a satisfactory soft-tissue correction has already been achieved. If this is not so, the surgeon may be faced with the 


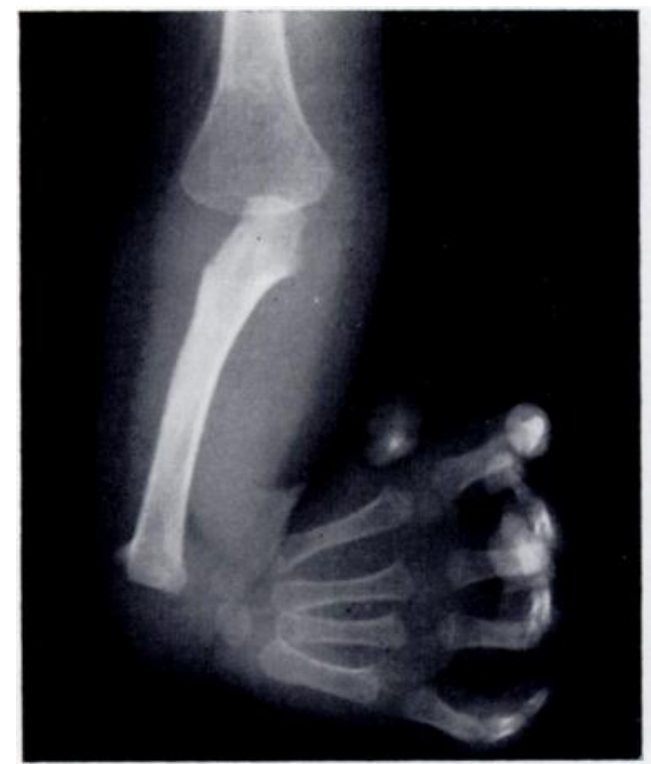

Fig. 4

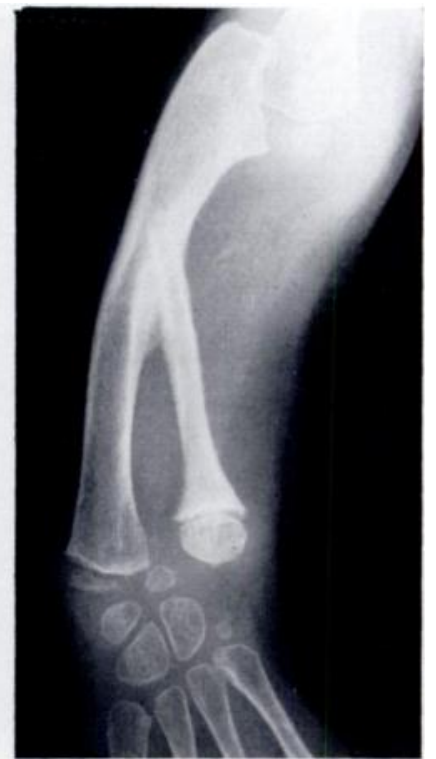

Fig. 5

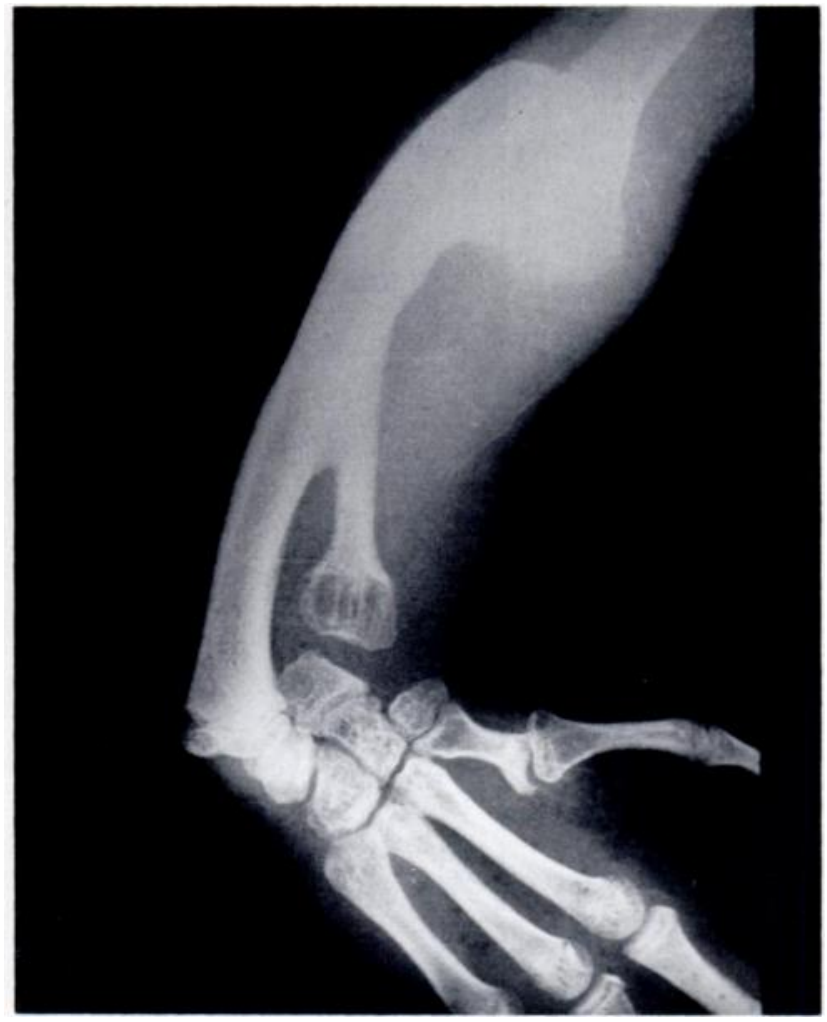

FIG. 6

Result after epiphysial transplant. Figure 4 -Age 3 years. Figure 5-Age 10 years; four months after fibular transplantation. Figure 6-Age 17 years. 
temptation to remove part of the ulnar head to overcome the technical difficulty of implanting it accurately-a temptation which must be resisted. Splintage from the first few weeks of life by a moulded Prenyl splint followed by a dynamic splint or ratchet splint (Lamb 1972) to maintain correction is usually effective. It may also be necessary, particularly when the patient is seen for the first time at an older age, to perform an open soft-tissue correction followed by dynamic splintage until the centralisation is performed.

At the time of centralisation, the ulnar head is placed into the space formed by removal of the lunate bone and part or all of the capitate. This position is held by a rod passed through

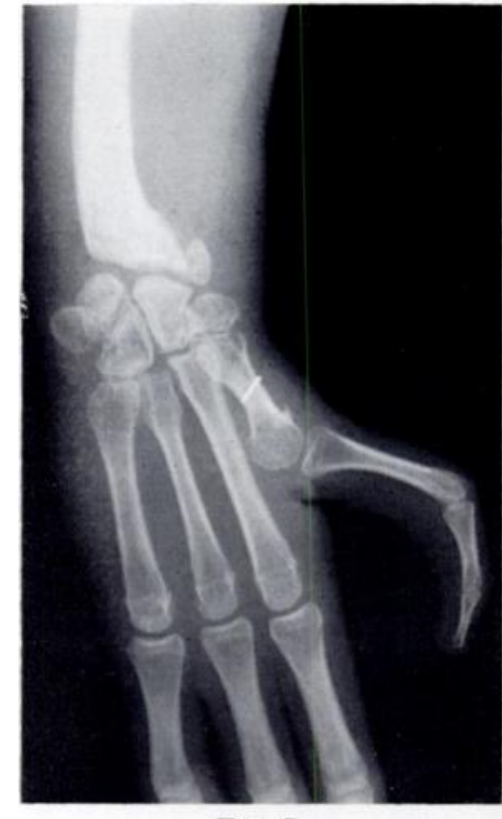

FIG. 7

Figs. 7 To 9

Results eleven years after centralisation of the carpus performed at the age of 5 years. Figure 7-Radiographs. Figure 8-Wrist extension. Figure 9-Wrist flexion. The index finger has been pollicised.
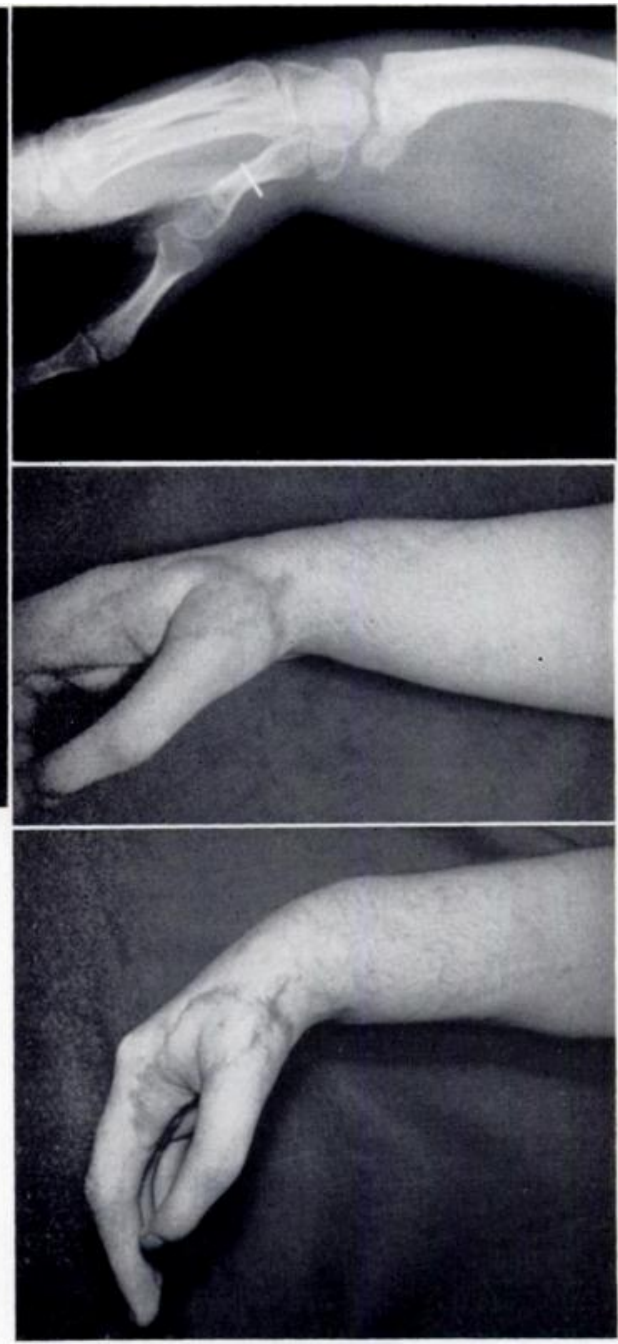

Figs. 8 AND 9

the third metacarpal bone and through the centre of the ulnar head, passing well up into the shaft. It has been my practice to remove this rod eight or ten weeks later, but some (Swanson 1957) prefer to maintain the rod, changing it when necessary for several years, and perhaps to maturity. After the removal of this internal splint, dynamic splintage is used until the position is stable. In some cases it has been found necessary to transfer flexor carpi ulnaris round the ulnar shaft to a new attachment on the dorsal aspect of the fourth metacarpal bone. Supervision is essential until growth has ceased in case deformity recurs and revision becomes necessary. 
The results are rewarding provided a correct position of the carpus is achieved and the ulnar epiphysis is not injured. In some cases a moderate movement develops at the ulnar-carpal junction, but more often firm fusion-fibrous or bony-occurs. The appearance is very much better but I cannot claim that the function is more than marginally improved, except for the occasional case (Figs. 7 to 9). Nevertheless, I have no personal doubt that this is the best that can be offered at the present time for this distressing deformity. Jones and Lovett (1929) tell of a young woman, "who was a housekeeper and applied for relief, not because her severe club hand was not useful in her work, but because of its unsightliness and shortening which led her always to conceal it in public".

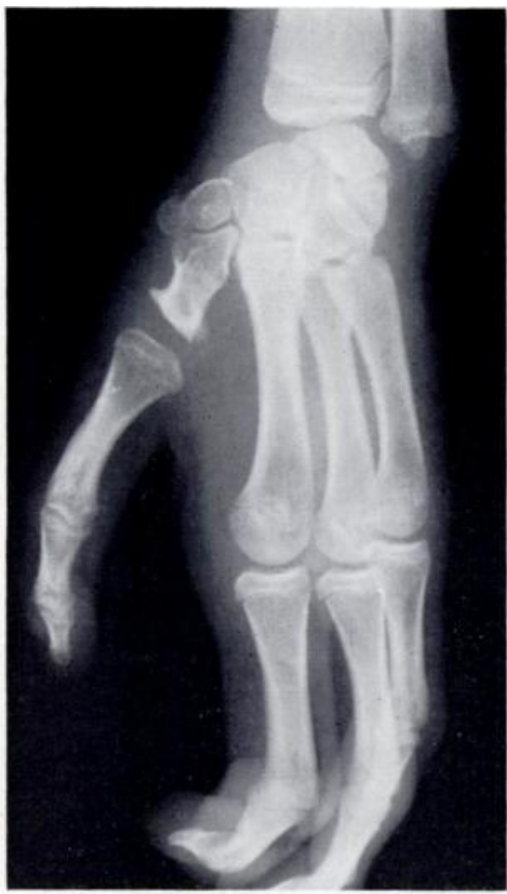

FIG. 10

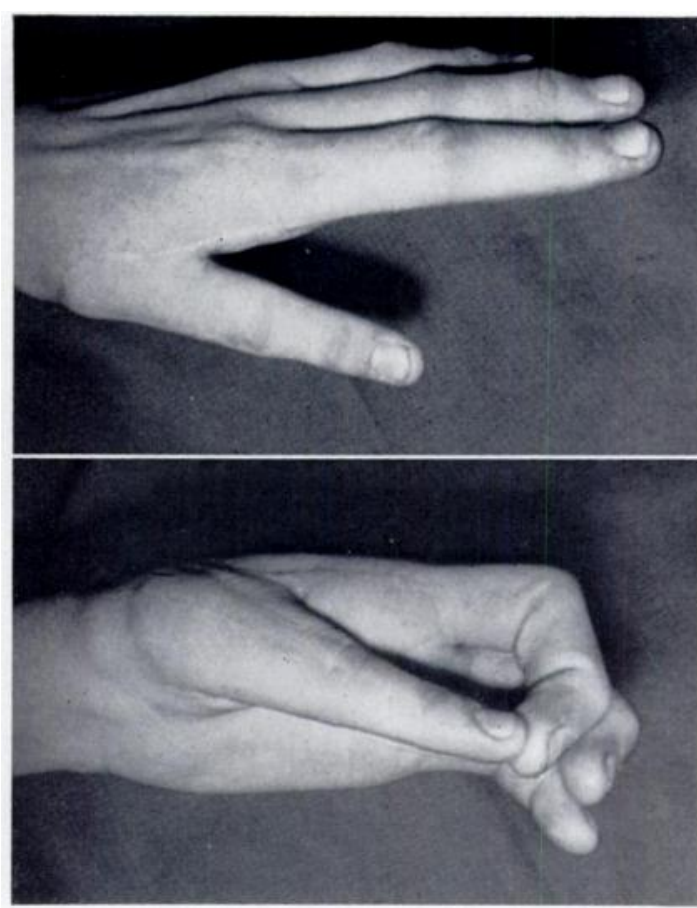

FIGS. 11 AND 12

Result ten years after pollicisation of the index finger for thumb aplasia, performed at the age of 6 years. Figure 10-Radiograph. Figure 11-At rest. Figure 12-In opposition.

\section{THE MISSING THUMB}

Some of our most grateful patients are those in whom a finger has been converted into a thumb, but a note of warning must be sounded. Pollicisation of a finger is justifiable only if the result is likely to be cosmetically and functionally rewarding. In some instances of thumb aplasia the fingers are so malformed and muscle action so poor that a useful thumb cannot be created. As a general rule, the index finger is the most suitable digit for transference. The modern technique evolved by Littler (1953) from the earlier work by Hilgenfeldt (1950) and Gosset (1949) is reliable and safe, yielding a thumb of correct length, good appearance and having the essential movements (Figs. 10 to 12). A pseudarthrosis may be formed between the proximal phalanx and the base of the second metacarpal bone or alternatively the metacarpo-phalangeal joint may be retained. The latter method is probably the better but has the disadvantage of providing a carpo-metacarpal joint with excessive movement and a thumb which is overlong. Buck-Gramcko (1971) has shown us how these problems can be overcome by rotation of the metacarpal head through 90 degrees and fixing it to the base of the resected metacarpal or directly to the carpus. 
The incompletely formed thumb may present a puzzling dilemma. There are many grades of this deformity. Some thumbs merely lack a muscle or two which can be rectified; others are diminutive with skeletal deficiencies-the "dangle thumb". In young patients it is tempting to perform a skeletal lengthening and attachment to the second metacarpal but the results are disappointing. Even when the epiphyses are intact, growth lags behind the rest of the hand

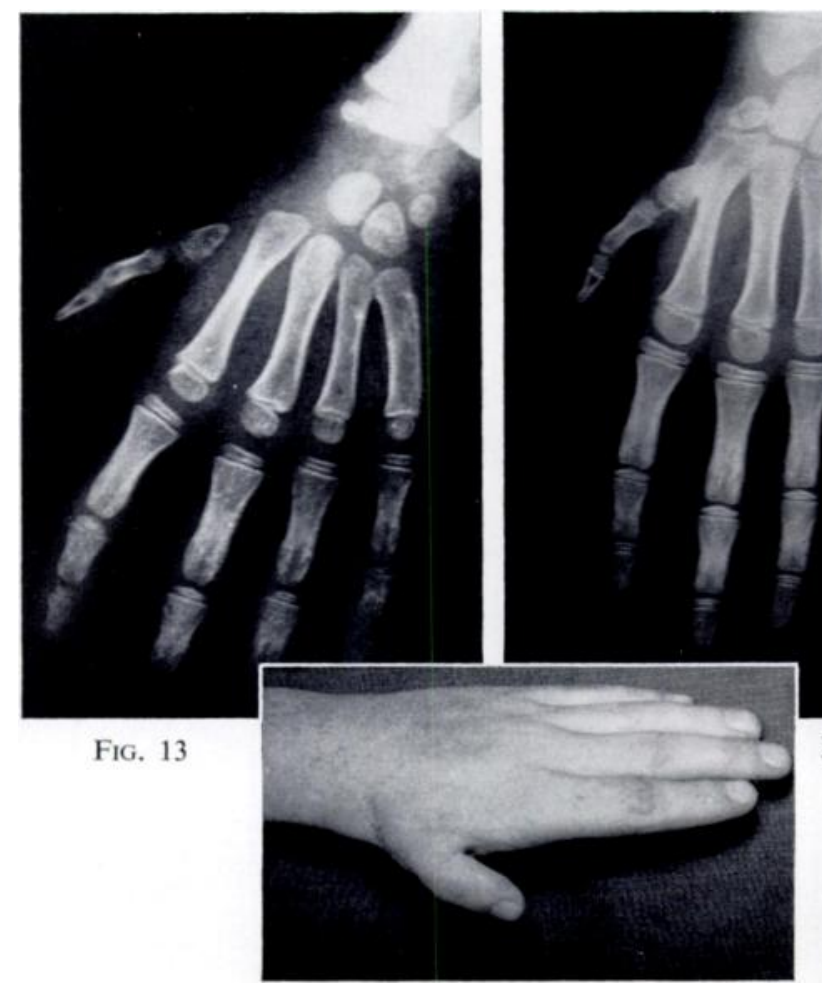

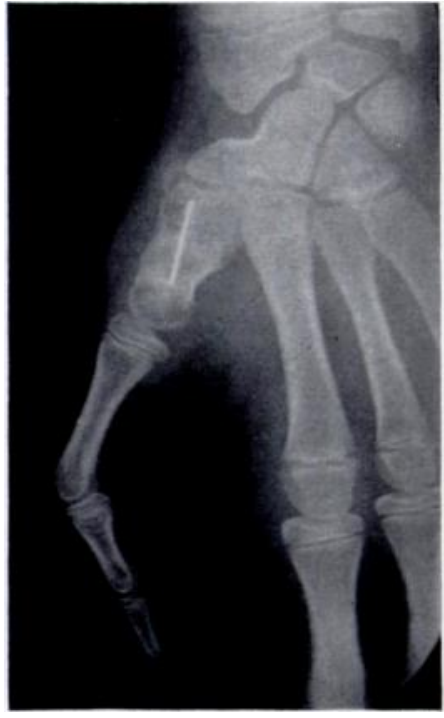

FIG. 15

Figs. 13 To 15

"Dangle" thumb. Figure 13-Age 5 years. Figure 14-Age 7 years; after grafting to the second metacarpal bone. Inset-Age 10 years; thumb diminutive. Figure 15-Age 13 years; after pollicisation of the index finger.

until eventually the thumb is so obviously undersized that it is not only functionless but cosmetically unacceptable. It is better to recognise this fact early and advise its removal and pollicisation of the index finger (Figs. 13 to 15 ).

\section{DUPUYTREN'S DISEASE}

This strange disease takes many forms and varies widely in its rate of progress. I have seen over 750 cases in twenty-five years. The disease may make its appearance at any age from adolescence to old age, with a marked progressive increase in incidence from forty years onwards. Treatment should be deferred until a stage is reached when correction is desirable. It is unnecessary to remove palmar nodules, which occasionally remain unchanged for years, unless they are an embarrassment to the patient. My own experience has led me to the view that the surgeon should be familiar with the several types of operation and choose the one which he considers is most suited to the particular case.

There are two types of operative treatment: fasciotomy and fasciectomy. Fasciotomy, which can readily be performed under local anaesthesia, is of value for the relief of isolated contracted bands in the palm. It should not be used in the digits because of hazard to the digital vessels and nerves. It is useful as a prelude to fasciectomy in patients with severe contraction in order to obtain some stretching of the shortened skin. The main indication is 
in the elderly and in selected patients in whom it is feared that complications may follow a more extensive procedure. Fasciectomy is advisable in the majority of cases, but there has been a tendency in recent years to perform a less extensive fascial removal than was previously practised (Hueston 1963). The fear of a higher recurrence rate is balanced by a more rapid convalescence and a lower incidence of complications (Barclay 1972).

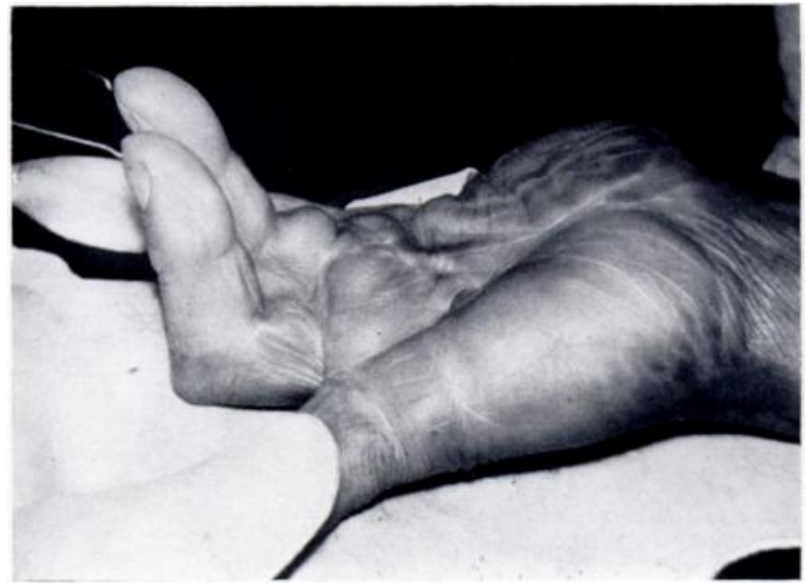

Fig. 16

FIGS. 16 AND 17

McIndoe's operation. Figure 16-Right hand before operation. Figure 17-At operation.

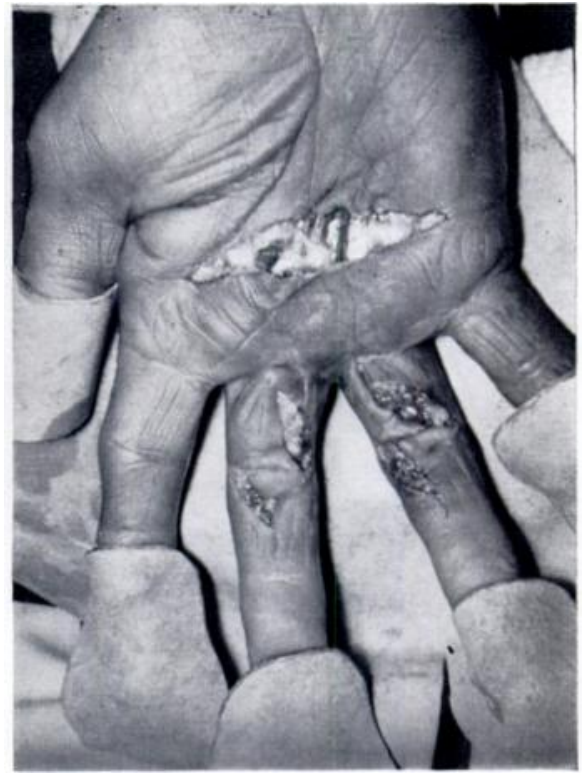

FIG. 17

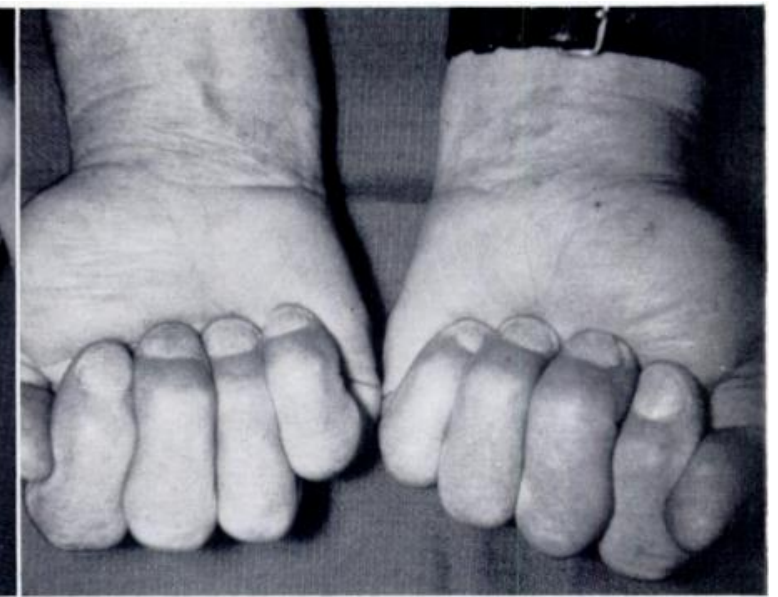

FIG. 18

Same case as above. Result three years later right hand; seven years after similar operation for ring finger contracture left hand. Age at operations 61 and 57 years respectively.

McIndoe's operation-excision of the palmar fascia including the transverse bands and the deep septa through an incision across the palm in the distal palmar crease, and of the finger fascia through a Z-plasty (McIndoe and Beare 1958) -is a satisfactory operation, providing the area between palm and digit is not excessively involved. In my experience correction has been good and complications have been few (Figs. 16 to 18). Skoog (1967), who has had an unrivalled experience of this operation, now restricts the palmar fasciectomy 
to the pre-tendinous bands, leaving the transverse fibres and the deep septa intact. He has found that this technique gives a more rapid recovery and that there is no apparent increase in the recurrence rate. This view I respect, but I have personally found no good reason to depart from the original method of McIndoe. In either form, the principles of the operation are sound, the results are good and the scars almost imperceptible.

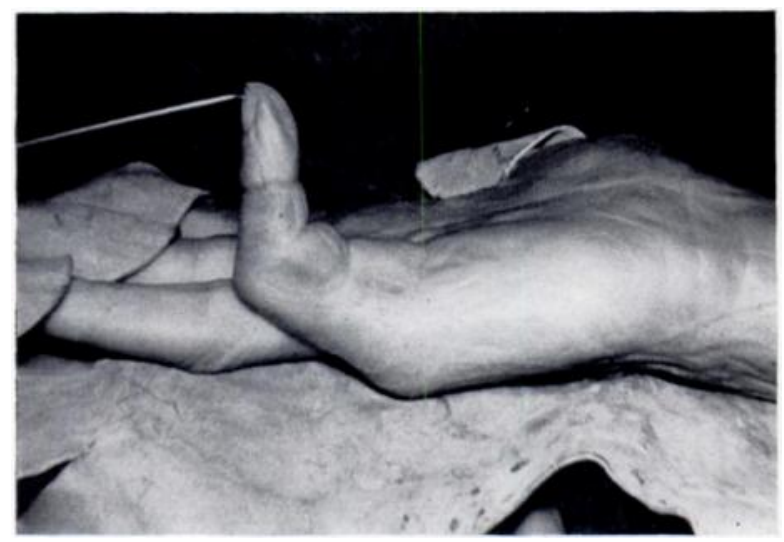

FIG. 19

Figs. 19 AND 20

Zig-zag operation. Figure 19-Before operation. Figure 20At completion of operation.

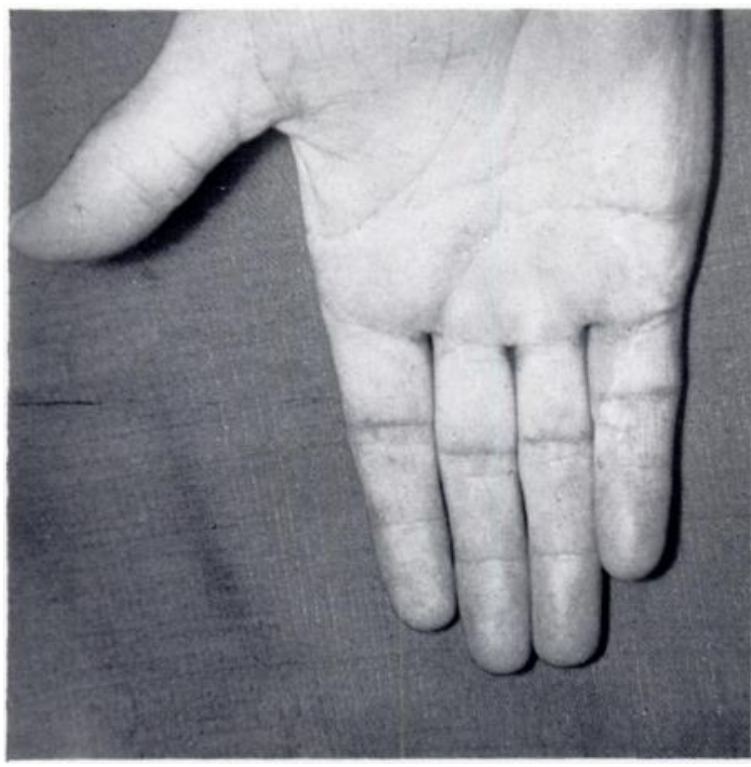

FIG. 21

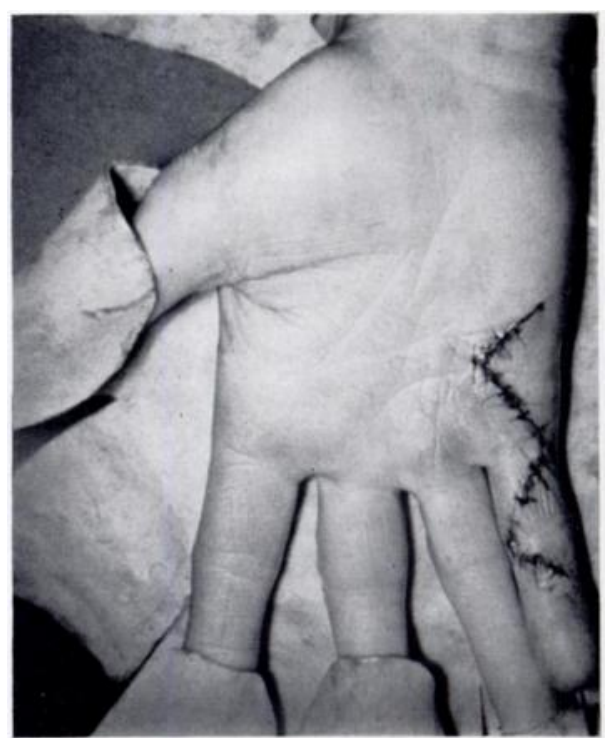

FIG. 20

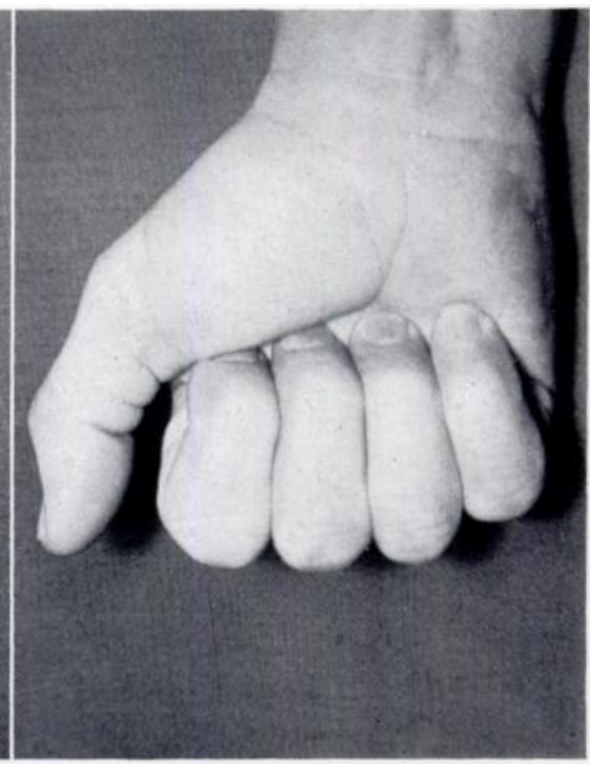

Same case as above. Result ten weeks later. Age at operation 69 years.

The zig-zag incision (Bruner 1967) provides an excellent exposure of the finger into the palm, and is, I believe, the method of choice when the base of the finger is heavily involved (Figs. 19 to 21). Care needs to be taken to fashion the flaps in such a manner that their blood 
supply is not embarrassed. There is no operative lengthening of the skin, but if necessary the skin shortening can be overcome during the few weeks after operation by dynamic splintage.

The mid-line incision with Z-plasty closure offers an alternative technique and affords positive lengthening of the skin (Fig. 22). It is sometimes difficult to fashion the small Z-plasties in the fingers; nor may the palmar skin lend itself kindly to this procedure.

The mid-lateral incision, or more accurately the mid-axial incision, is suitable when the ulnar side only of the little finger and distal palm are affected. It is essential not to site the incision anterior to the mid-axial line, for if this is done there is a risk of scar contracture. The skin is lifted forward from the vessels and nerve and the thickened fascia is clearly exposed.

The open palm method described by McCash (1964) follows the McIndoe technique but the palmar wound is left open and the skin edges are sewn down to the deeper structures. The metacarpo-phalangeal joints are held by splintage in the extended position. The palmar wound heals by normal skin in approximately five to six weeks and forms a near linear scar. This innovation was at first received with some surprise and scepticism, but those who have

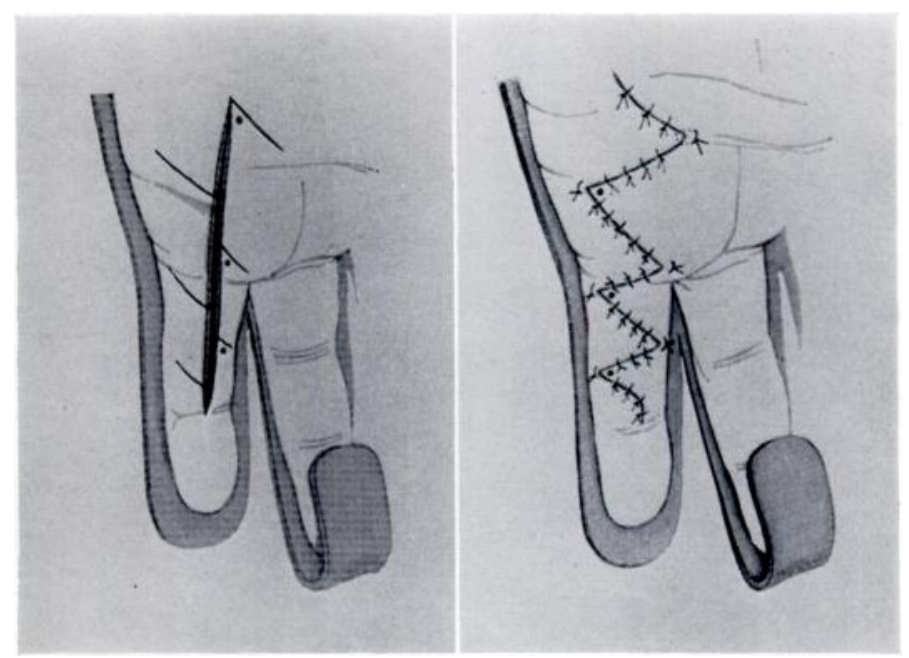

Fig. 22

Mid-line and Z-plasty operation: skin technique.

used it have come to regard it as a valuable technique for those hands in which the palmar skin is very contracted and in which skin grafting or a local skin flap might otherwise be required. The cross-arm flap-There are cases, particularly in younger patients, in which the skin at the base of a finger is so severely involved that complete skin as well as fascial excision is required if the finger is to remain permanently corrected. Under these circumstances, replacement of skin and subcutaneous tissue by a flap taken from the opposite arm or forearm offers a solution. The indications are few, but the result can be most rewarding (Figs. 23 to 25).

The staged operation-Circumspection is desirable when planning the treatment of any hand afflicted by Dupuytren's disease. This is particularly true for the hand with widespread involvement. In such a case the correction is best performed in stages. Contracture affecting the metacarpo-phalangeal joint is corrected by palmar fasciectomy. Some months later, when the hand has completely settled, digital fasciectomy is performed. By this means a reasonable correction can be obtained in difficult cases without undue risk (Figs. 26 and 27).

Finally, one must add that when the deformity is very severe and of long standing, correction may not be possible and selective amputation is the only means of reducing the overall disability. 


\section{TENDON GRAFTING}

The first account of a human tendon grafting operation was in 1889. In that year Mayo Robson of Leeds described a case in the Transactions of the Clinical Society of London in which he had successfully transplanted eleven centimetres of a flexor tendon to replace an extensor

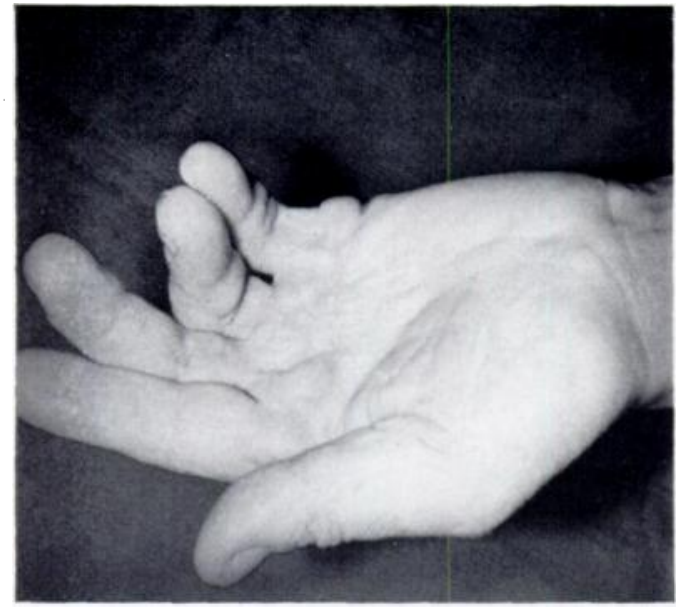

FIG. 23

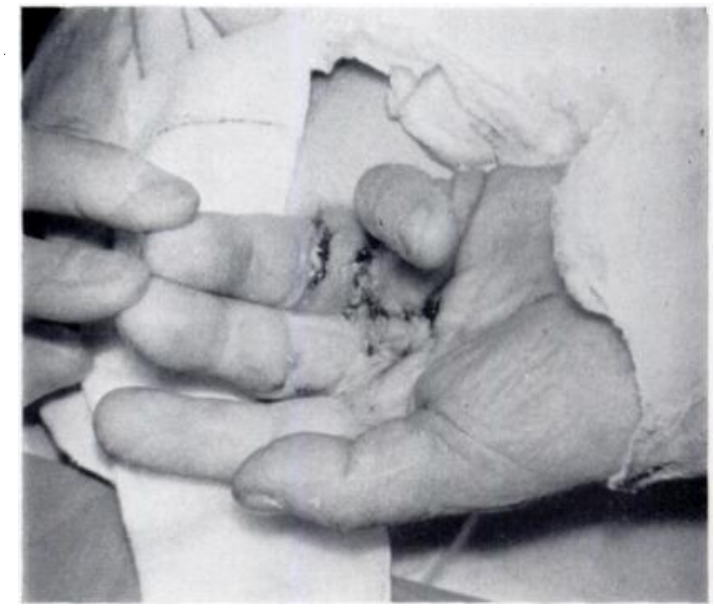

FIG. 24

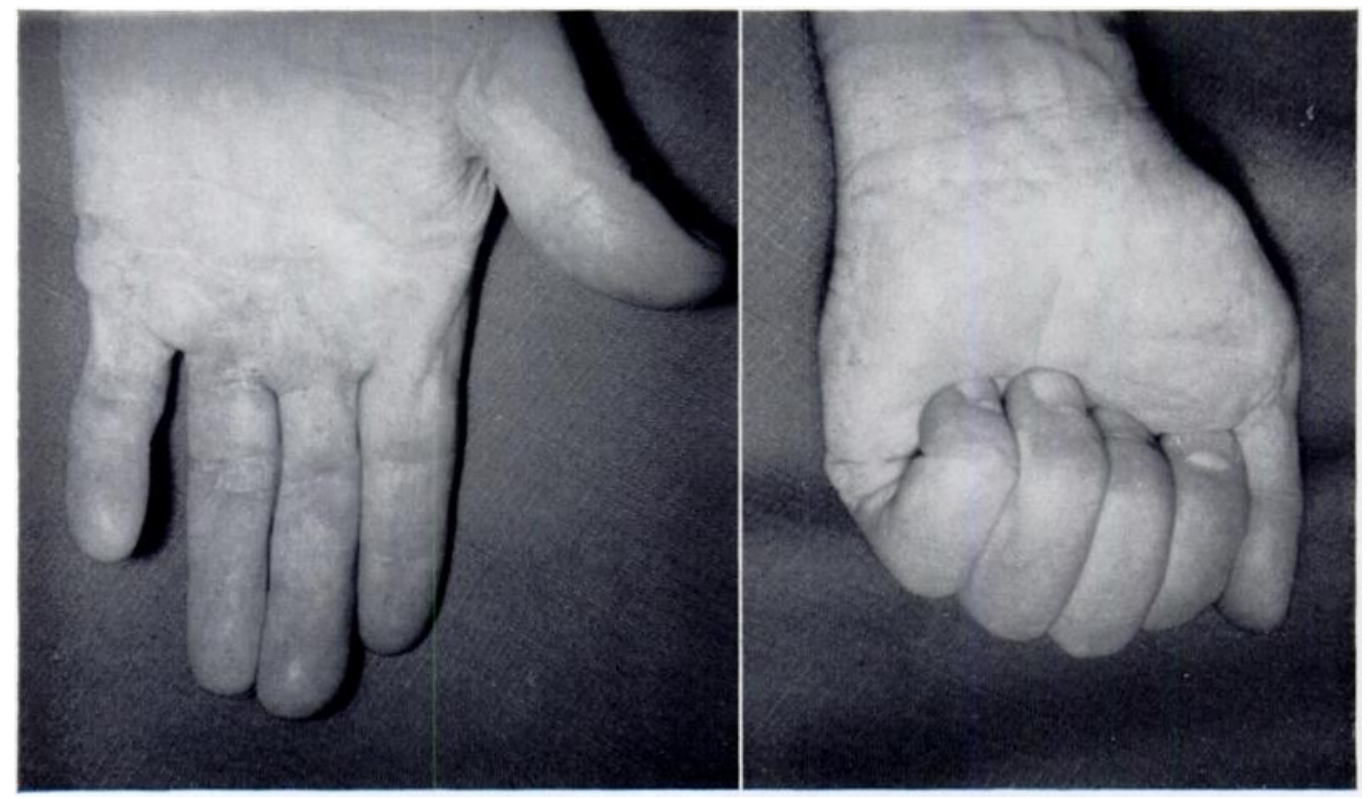

FIG. 25

Cross-arm flap operation. Figure 23-Before operation. Figure 24-During attachment. Figure 25-Result ten weeks later. Age at operation 54 years. Onset of disease at age 28 years. Five previous operations.

tendon. In 1918 Bunnell recommended the use of a free tendon graft to replace injured flexor tendons in the fingers. In 1922 he reported five similar cases with good results. There is much to be learned from this classic paper with its insistence upon the necessity for a gentle and accurate technique. It is upon Bunnell's teaching that the structure of hand surgery throughout the world has been based, and especially so in respect of the treatment of tendon injuries. 
A tendon heals by proliferation of the synovial layer of the sheath or from the paratenon, and the tendon itself or a tendon graft contributes little, if anything, to this process. A free tendon graft remains viable and apparently there is no gradual replacement of its cells. The links between the tendon ends and the surrounding tissue gradually resolve or stretch to permit the tendon to move. It follows that every care must be taken by the surgeon to avoid injury to the surface of the tendon or graft which would cause unnecessary and probably dense adhesions which may not resolve. Precise and gentle surgery is essential for successful results.

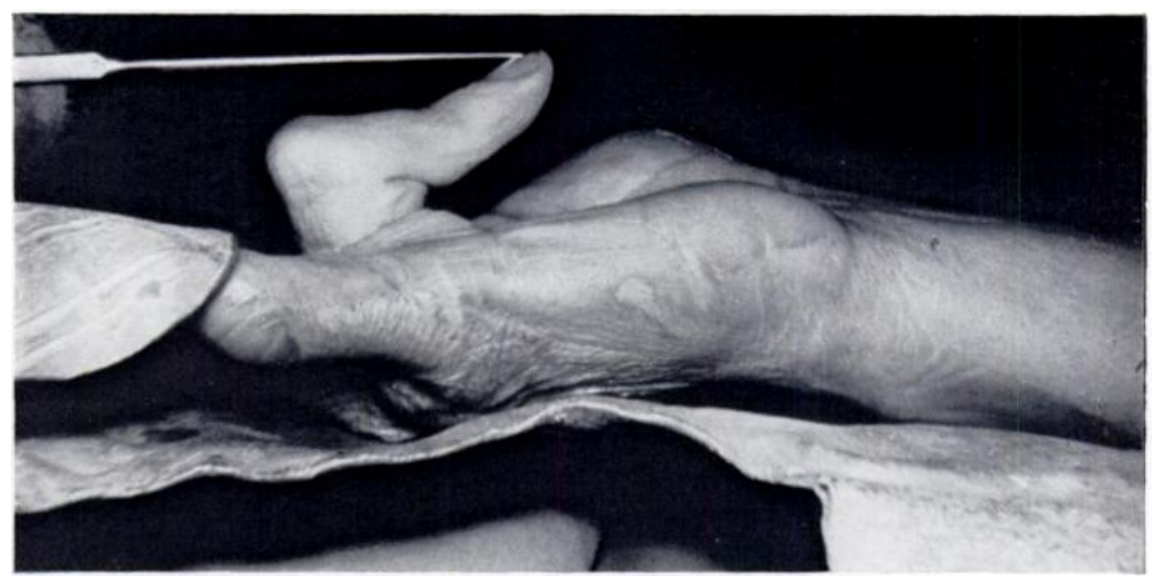

FIG. 26

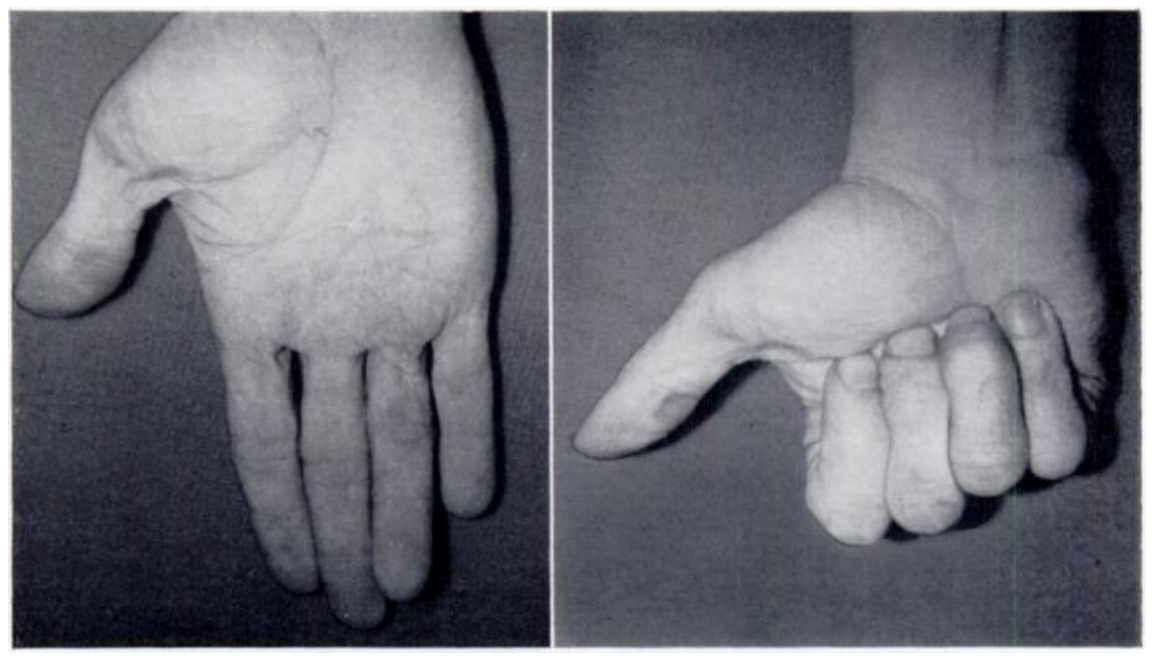

FIG. 27

The staged operation: fasciotomy, palmar fasciectomy and finally finger fasciectomy by zig-zag incision. Figure 26-Before operation. Figure 27-Result eight months after last stage.

A tendon absent by congenital fault, destroyed by rheumatoid disease or by infection, or divided by injury may be replaced by a graft. A tendon transposed to serve a different function may, if necessary, be extended by a graft to reach its new attachment. Tendons are always available in the patient and there is no need in normal practice for the use of homogenous grafts. The tendons commonly chosen are plantaris, palmaris longus and the long extensor tendons of the toes. Flexor digitorum superficialis is suitable for a short bridge graft. 


\section{REPAIR OF FLEXOR TENDON INJURIES OF THE DIGITS}

It is impracticable to include all the applications of tendon grafting and only their use for this restricted field will be discussed.

Flexor digitorum profundus-Division of flexor profundus distal to the superficialis attachment may be treated by immediate suture with an excellent expectation of success. When the tendon is divided in the proximal part of the finger and the superficialis remains intact, skin suture only is the correct primary treatment and the tendon injury is ignored at the time. I have seen some unhappy results following primary suture of profundus under these circumstances. When it comes to secondary repair, whether it be because the injury was overlooked or because of deliberate policy, there is a choice of treatment and the decision depends upon several factors. In the distal part of the digit secondary suture is possible, provided retraction and muscle shortening does not prevent end-to-end apposition without tension. Lengthening the profundus tendon in the palm is not a method that appeals to me and I have seen bad results from this technique.

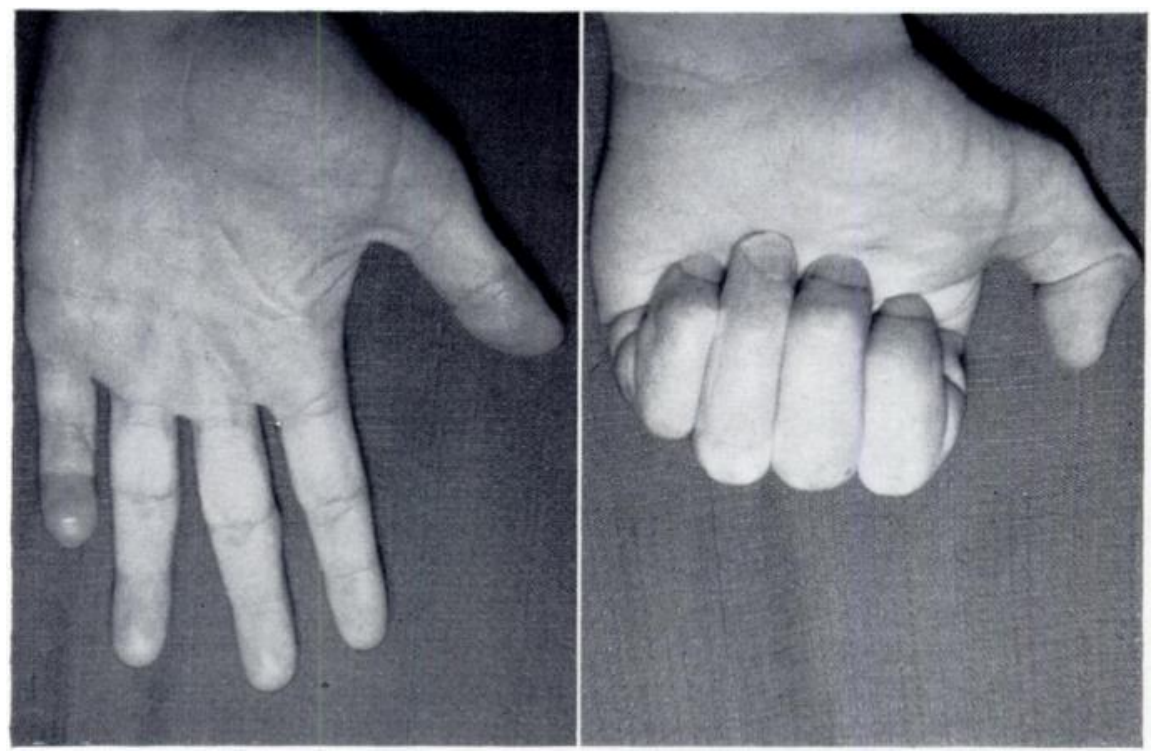

FIG. 28

Result after tendon grafting for profundus division at level of proximal interphalangeal joints in all fingers. Toe extensor tendons were used as grafts, the plantaris being absent.

When direct suture is impossible or difficult to perform, and in all proximal divisions with an intact superficialis, the choice lies between acceptance of the disability, arthrodesis of the distal joint (or tenodesis) or replacement of profundus by a free tendon graft (Pulvertaft 1960). The decision depends upon the patient's age, the overall condition of the finger and hand and the occupation and wishes of the patient. The operation of grafting is one of some magnitude for what is a comparatively small disability. It should not be done unless the patient is determined to seek perfection and the surgeon is confident of his ability to offer a reasonable expectation of success without risk of doing harm. It is my practice to offer tendon grafting for the index and middle fingers in the majority of persons in order to restore the thumb-finger pinch. I advise it for the ring and little fingers when the patient requires this action on account of a special interest or occupation, such as a musician or skilled technician. For those employed in general labour and for all who desire a quick and certain result of a less perfect nature, I believe it is better to arthrodese the distal interphalangeal joint. For 
children, I advise grafting because the lengthy recovery period is of no significance and no one can foresee the child's future requirements. Good function has been restored in 80 per cent of cases, and in the patients in whom this objective was not achieved there has very rarely been any disturbance of the existing sublimis action (Fig. 28).

Flexor digitorum profundus and superficialis-In 1948 Bunnell said: "Poor results the world over follow suture of flexor tendons in what is called "no man's land", that is between the distal crease of the palm and the middle flexion crease of the finger". Bunnell formed this opinion as the result of seeing many poor results of primary and secondary suture in this region. Not only were the results poor, but the prognosis of subsequent grafting was worsened because of scarring of the tendon bed. He advised secondary tendon grafting as the routine treatment for this injury and this doctrine has been widely accepted and practised. My own experience (Pulvertaft 1956) has confirmed this view (Fig. 29), but there are others who have consistently practised suture immediately, or after a few days' delay, with results comparable with, and in some reported series (Verdan 1972) even better than, those obtained by grafting. Verdan

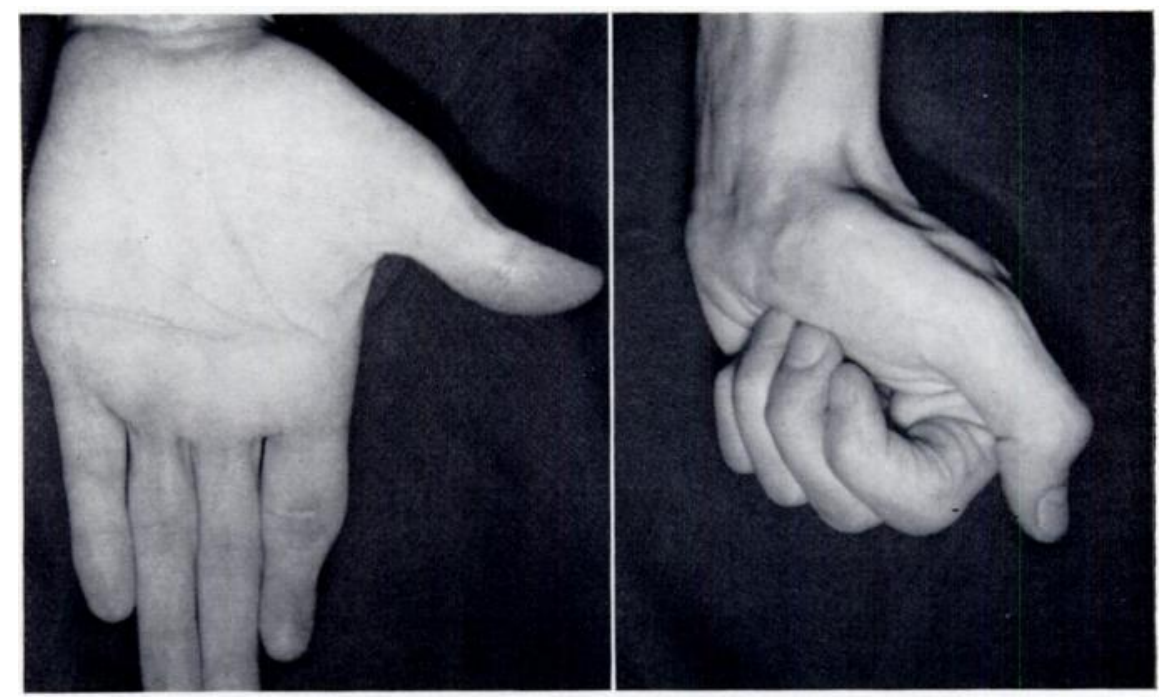

Fig. 29

Result after tendon grafting for superficialis and profundus division in all fingers. Toe extensor tendon used for index, palmaris for middle and plantaris for ring and little fingers. Variation due to technical reasons. Index finger had also sustained open fracture of proximal phalanx.

considers that there is a good case for immediate repair of both the superficialis and profundus tendons. As the general standard of emergency surgery improves, primary suture may become the method of choice, but it must be stressed that these good results can be attained only by those who are masters of technique. When skill of this order is not available it is wiser to limit the emergency treatment to wound closure, to ensure rapid healing, and to work towards a fully mobile finger in preparation for secondary grafting.

From time to time a patient is seen several years after a tendon has been divided within the digital theca. Previous surgery may have failed or the patient has been told that there is no effective treatment for this injury. Function can be restored in a high proportion of these cases and the surgeon experienced in this work should not hesitate to advise reconstruction, provided there is good passive movement and sensibility.

A recent study of the results of grafting after long delay (Pulvertaft 1972) revealed to my surprise that these results were slightly better than those in which operation was performed 
within a few months of injury (Fig. 30). The average interval between injury and surgery in the delay series of superficialis and profundus loss was five years. In all cases of both series one of the original muscles of the injured digit was used (Fig. 31), although on reflection it would have been wiser in a few of the cases to have transferred a superficialis muscle from an adjacent finger. The improved results can be explained in part by the fact that the pre-operative condition in the delay cases was better than in the general series; in other words, a stricter selection for operative suitability was made. The average age (fifteen years) was lower than in the general series (twenty-four years). The lesson to be learned from these observations is that delay is not necessarily prejudicial to the result, and that it is advantageous to allow a lapse of four to six months to allow the tissues to recover from the initial injury. This is of special significance in the treatment of children, for the very young cannot co-operate

FLEXOR SUPERFICIALIS AND PROFUNDUS

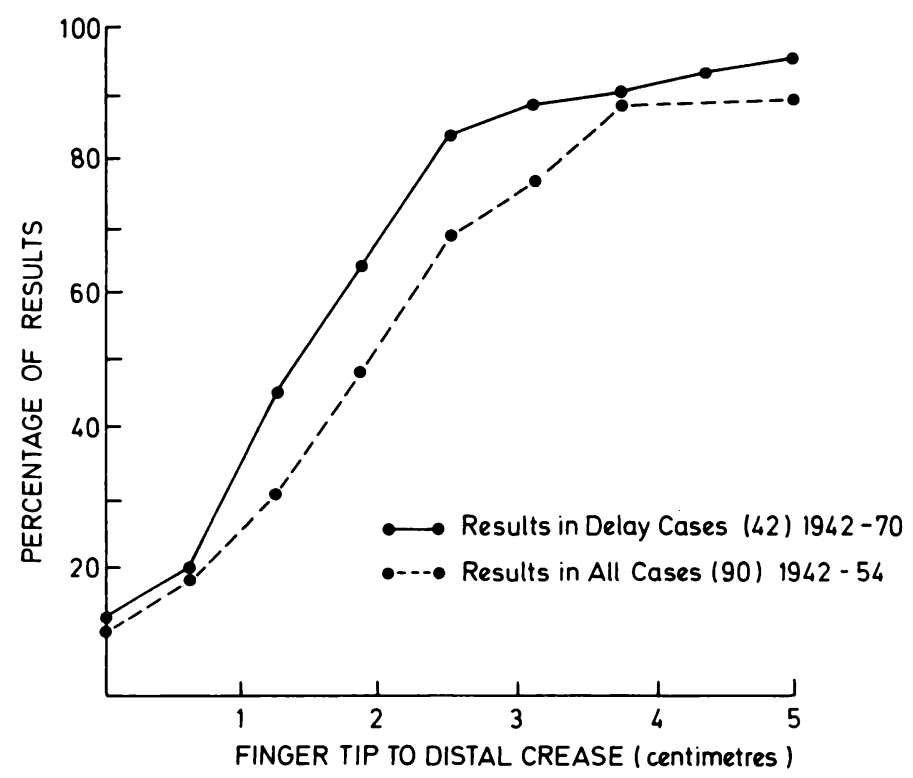

FIG. 30

Comparison of results in two series of tendon graft operations for severance of flexor superficialis and flexor profundus tendons: delay cases (see text) treated between 1942 and 1970 (forty-two) are shown by continuous line; and all cases treated between 1942 and 1954 (ninety) are shown by broken line. The graphs indicate range of flexion as gauged by distance from finger tip to distal palmar crease. In the delay cases extension was complete except that the proximal interphalangeal joint lacked 30 degrees of extension in two cases and 20 degrees in three cases; and the distal interphalangeal joint lacked 40 degrees in one case, 30 degrees in three cases and 20 degrees in one case. In the other series (all cases 1942-54) extension was complete in all except that the proximal interphalangeal joint lacked 30 degrees in twelve cases and between 5 and 30 degrees in seventeen cases.

in the after-care which is essential for success. Consistently good results have been obtained by delaying the grafting operation until the child has reached the age of four years.

Flexor pollicis longus-Primary suture of flexor pollicis distal to the metacarpo-phalangeal joint yields good results. The less common cases of division deep to the thenar muscles may also be treated by primary repair but the exposure is difficult because the tendon lies in close proximity to the sensory nerves of the thumb and the motor branch to the thenar muscles. Accidental division of one or more of these nerves will create a more troublesome fault than 
loss of flexion of the distal phalanx. The results of secondary tendon grafting are good ( 80 to 90 per cent successful). For these reasons my advice to the inexperienced is not to perform primary suture in this area unless the hand is already laid open by the injury; under these circumstances full examination and repair of divided structures is clearly required.

The palm-The palm may be subdivided into three regions: proximal, middle and distal. In the proximal region the tendons are closely grouped together and several or all may be injured by a stab wound. In the middle region the tendons have spread out and it requires an extensive wound to divide all the tendons. Injuries in the distal region divide the tendons within the digital theca.

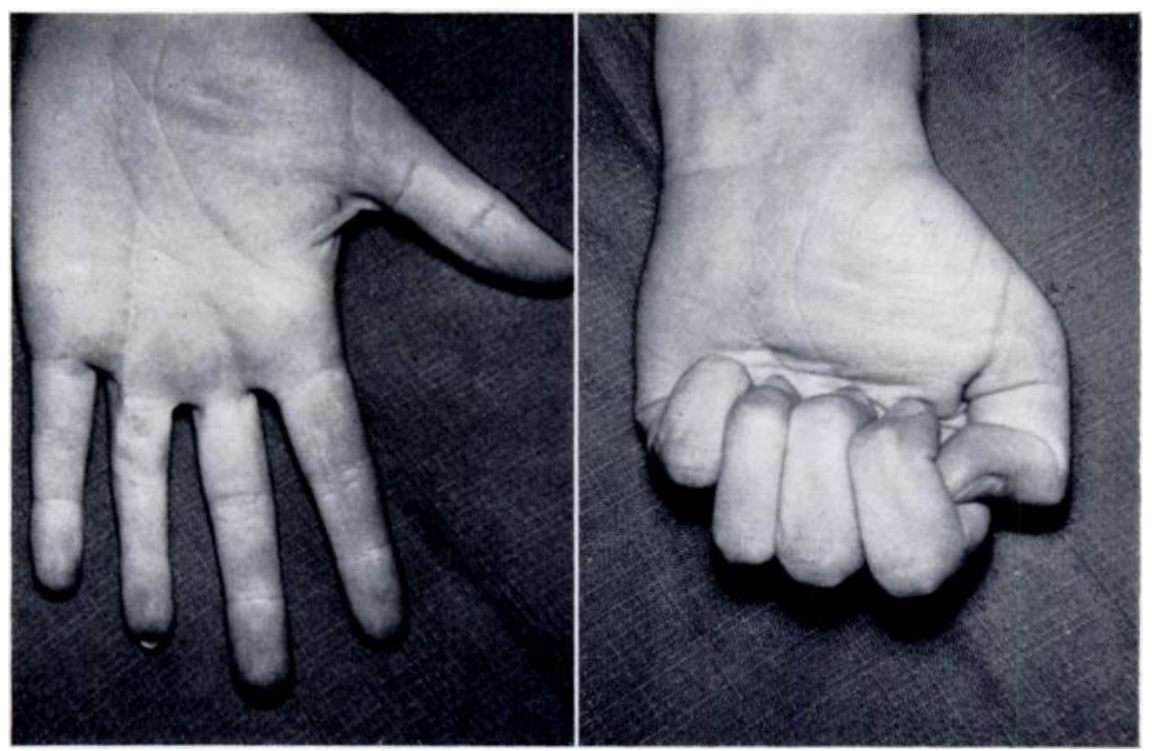

Fig. 31

Result after tendon grafting for superficialis and profundus division in the ring finger. Plantaris tendon used as graft and superficialis of injured finger used as motor. Injury at age 18 months. Operation at age $12 \frac{1}{2}$ years. The unusual scar line follows a previous operative incision.

In the proximal and middle regions primary repair is the correct treatment. It is probably wiser to suture profundus and ignore superficialis: there is a risk of cross union and loss of profundus action if both tendons are repaired at the same level. When primary suture has failed or has not been performed, the tendon ends separate and it may be impossible to obtain end-to-end contact. A short graft taken from superficialis may be used to bridge the gap in profundus and restore continuity. Provided the scarring is not severe, good results can be obtained by this technique.

The tendon prosthesis-A discussion of tendon grafting would be incomplete without mention of the tendon prosihesis. In 1936 Mayer and Ransohoff reported the use of Celloidin tube implants in scarred fingers as a prelude to tendon grafting. They showed that a pseudo-sheath formed around the tube into which the graft could be inserted. The clinical results were disappointing because the finger stiffened during the period that the rigid rod was in place. Milgram (1960), using stainless strips in the forearm and leg, confirmed this concept and reported successful results in severely scarred limbs. He demonstrated that a bursa-like sac developed through which a tendon graft would slide. Bassett and Carroll (1963) reported successful results following the use of a flexible implant made of silicone rubber. They 
reserved the procedure for patients in whom ordinary tendon grafting was not likely to succeed. This was a major step forward.

Hunter (1965) confirmed this work and introduced a silicone-rubber prosthesis reinforced with Dacron. In 1971 Hunter and Salisbury described the technique and the results in detail. The operation is performed in two stages. At the first stage scar is removed, contractures are corrected and a new pulley system is constructed if it is required. The prosthesis is inserted and attached to the distal phalanx. The proximal end is left free in the tissues above the wrist. After an interval of two to four months, during which time passive movement is developed, the implant is replaced by a tendon graft. Their results are impressive and there is no doubt that this method of treatment provides a way of restoring function that would otherwise be impossible to achieve. The procedure is reserved for properly selected old injuries where the conditions are less than optimal for tendon grafting.

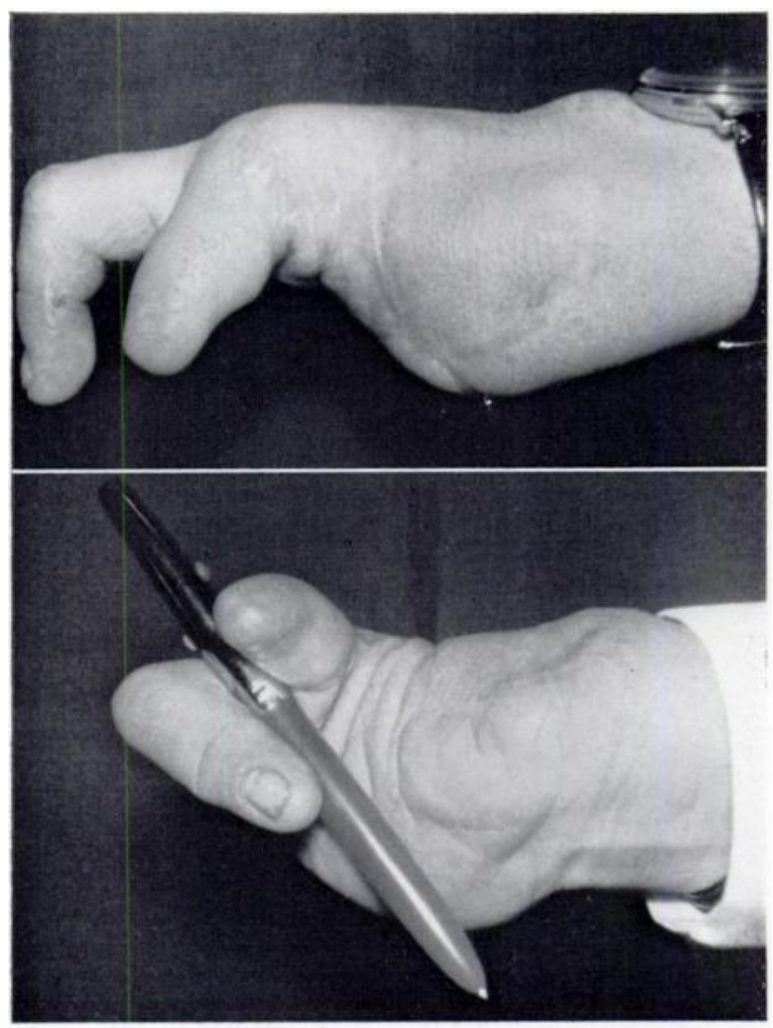

Fig. 32

Showing the value of a finger fragment in a mutilated hand. Explosion injury at age 13 years. Amputation of left hand. The patient works as a clerk.

\section{PRESERVATION OF COMPOSITE TISSUES}

The appearance of a disrupted hand may be daunting and it is tem ting sometimes to think in terms of amputation-quick to perform and free from complications but very final in its effects. Our object is to build from the wreckage a hand which is capable of a grasp better than can be offered by a prosthesis and with sensibility, which no prosthesis can provide. The philosophy of functional restoration demands that we view the mutilated hand with eyes that are trained to see what can eventually be restored; in other words, to recognise the potential. The ability to do so stems from a combination of technical proficiency and wisdom gained from experience. 
A distinction must be made between the hand with widespread injuries and the hand in which only one or two digits are affected. In the first instance the principle of preservation of viable parts holds good, but the attempted restoration of a single finger damaged beyond hope of reasonable movement and sensibility is to burden a hand with a liability. A finger which

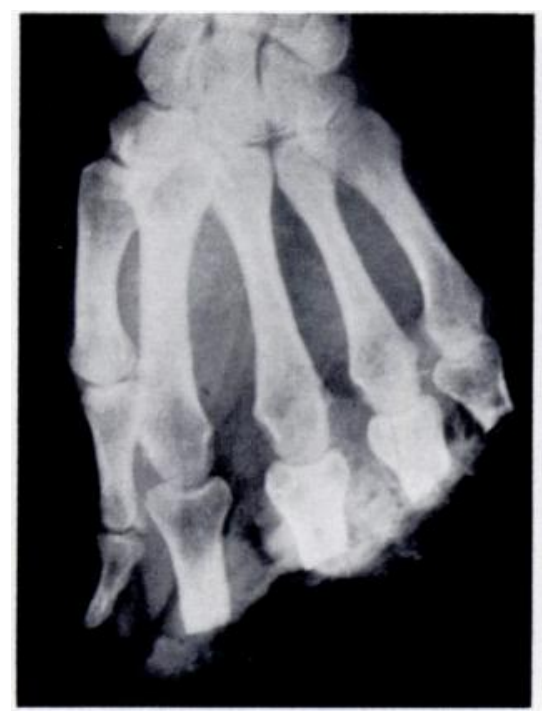

FIG. 33

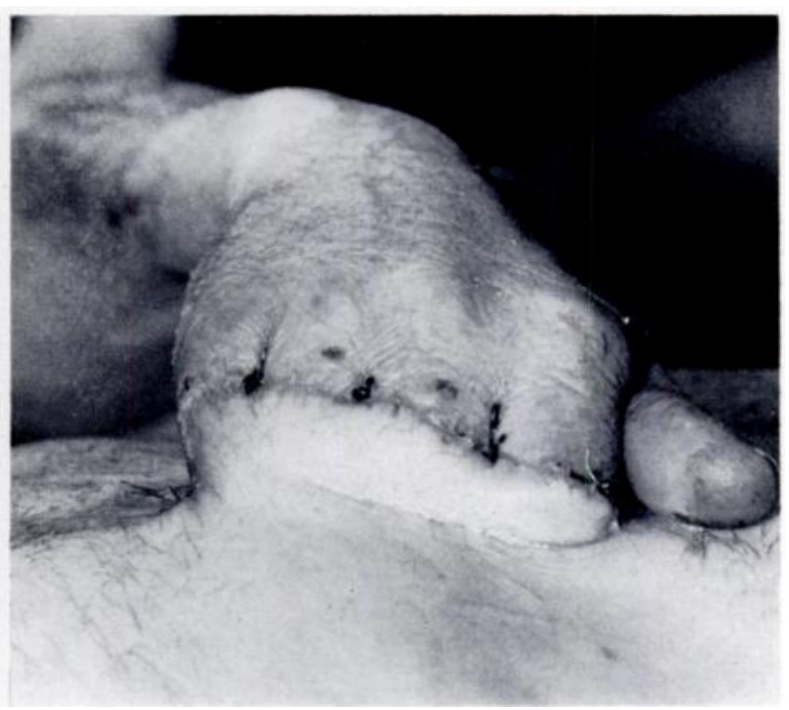

FIG. 34

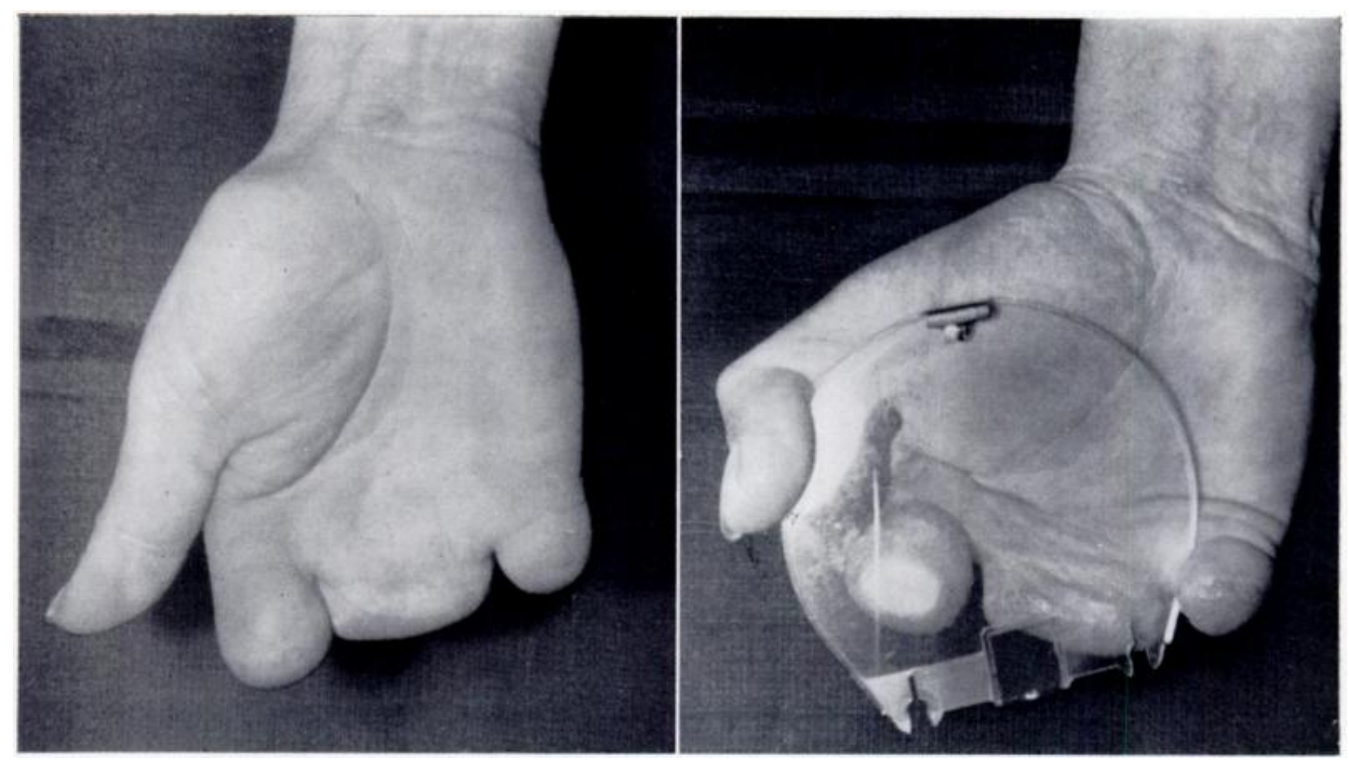

Fig. 35

Guillotine amputation of all fingers. Figure 33-Initial radiograph. Figure 34-Immediate abdominal flap: separation of stumps of fingers later. Figure 35-Condition four years after the injury.

has suffered a ring avulsion can be preserved but is of little functional use to the hand. I believe that amputation, as advised many years ago by Watson-Jones (1943), is the proper management of this injury. In contrast, the young man whose hand is shown in Figure 32 was thankful to have a short finger stump preserved because it provided, with his one intact finger, the only grasp that he possessed.

VOL. 55 B, NO. 1, FEBRUARY 1973 
Maintenance of finger length may be a mistake if it means poor sensibility of the finger extremity, but when all the fingers are lost as in the case illustrated in Figures 33 to 35, it is advantageous to keep as much length as possible by the use of a skin flap.

The potential of the hand shown in Figures 36 and 37 was not immediately obvious but fortunately it was saved by placing the limb beneath the abdominal skin. This supplied cover for the dorsal surface and later a free skin graft was applied to the volar surface. Subsequent deepening of the thumb cleft gave a useful grip which has served the patient for twenty-five years.

In ulnar hemi-amputation a reasonable grip remains provided the metacarpal bones are not lost. When the amputation occurs through the metacarpus, the ulnar side of the hand can be built up later to form an opposing structure to the thumb. In the case shown in Figures

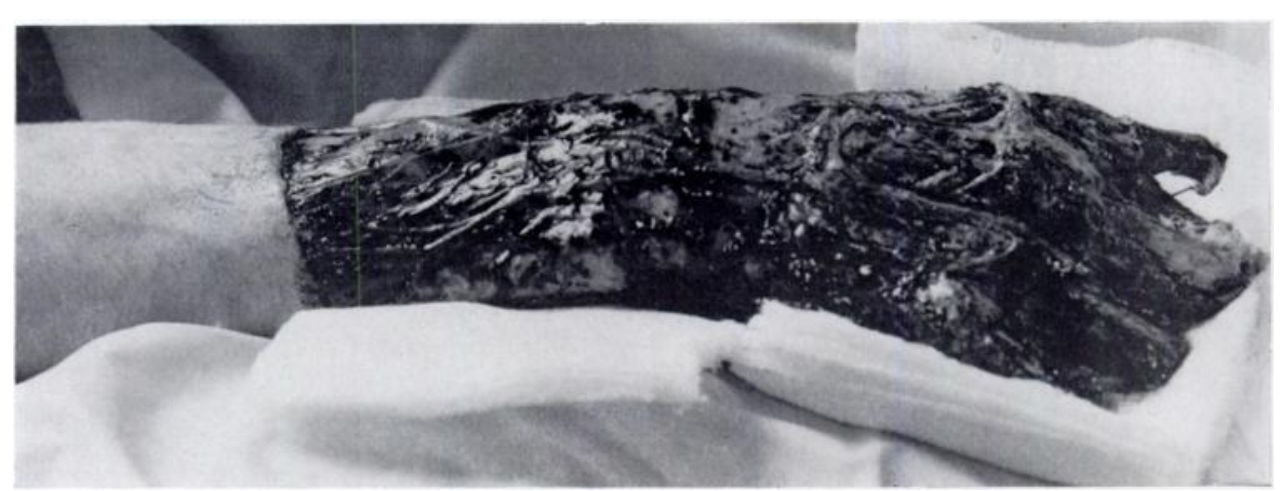

FIG. 36

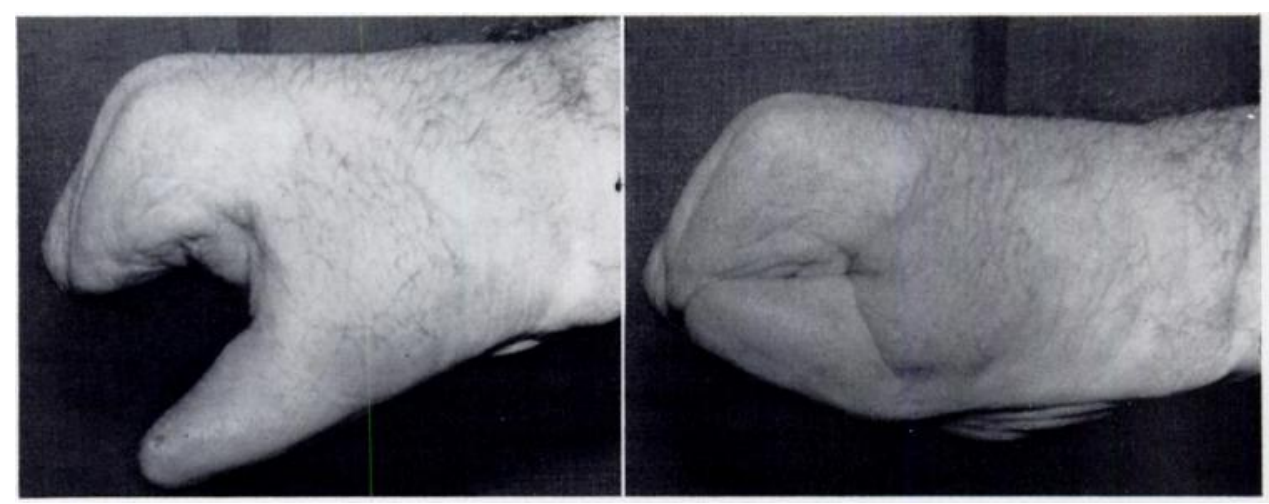

Fig. 37

Roller injury. Figure 36-Initial photograph. Figure 37-Result seventeen years after the injury. The patient works as a storeman.

38 to 40 the future requirements were recognised at the time of the emergency operation. A bulky skin flap was attached to the hand, into which an iliac bone graft was subsequently inserted.

When the thumb is lost, the surgeon should pause before he removes a finger so damaged that its own function cannot be restored, because the finger may provide material for thumb reconstruction later. In the patient whose hand is shown in Figures 41 and 42, gunshot wounds caused sub-total thumb loss, shattering of the second metacarpal bone and severe damage to the index finger. He was advised soon after the injury to have the useless finger removed, 


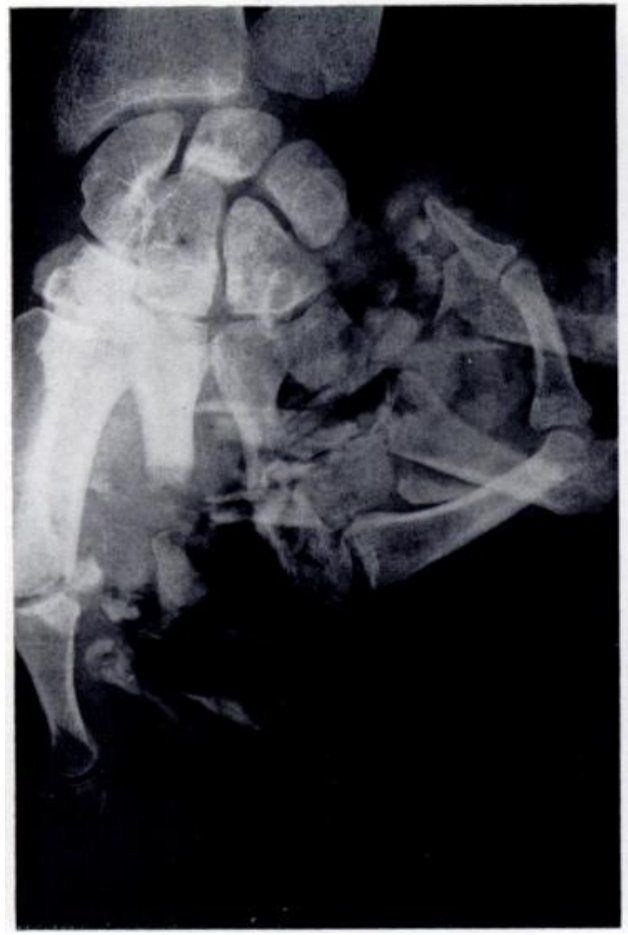

Fig. 38

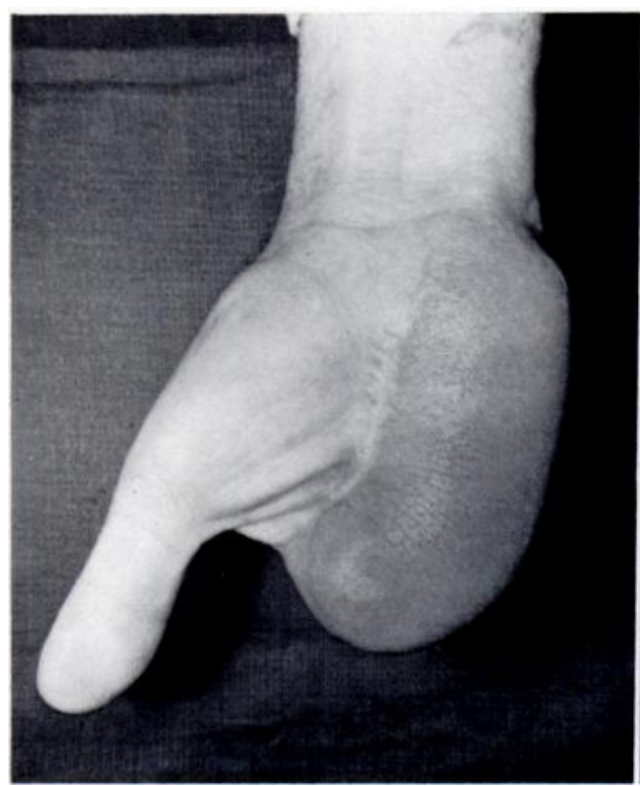

Fig. 40

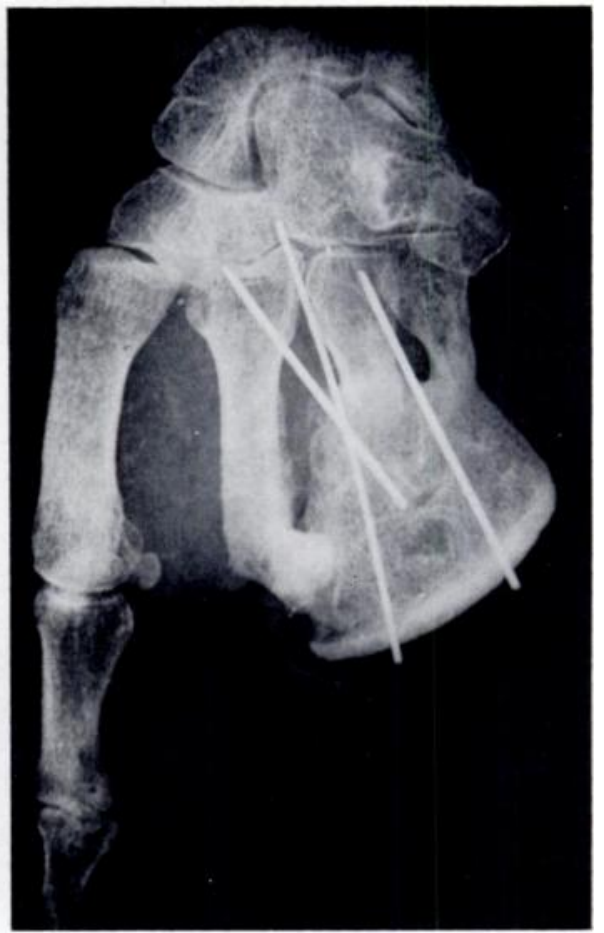

Fig. 39

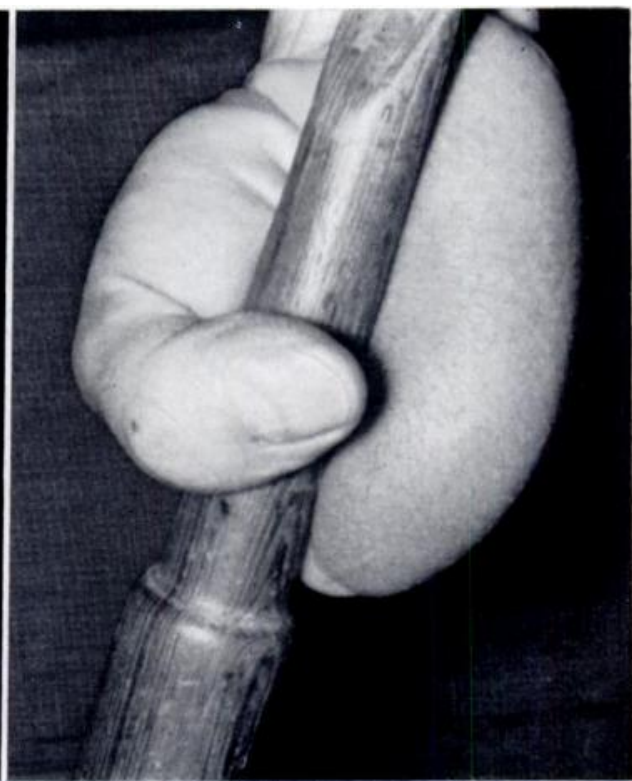
Press injury. Figure 38-Initial radiograph. Figure 39-After immediate abdominal flap and later iliac
bone graft. Figure 40 -Condition seven years after injury. The patient works as a diesel train driver.

VOL. 55 B, No. 1, FEBRUARY 1973 
but he refused in the hope that something might later be made of it. Destruction of the vessels on the radial side and extensive scarring rendered pollicisation hazardous. Arteriography revealed that the ulnar vessel was intact and the operation was performed, materially improving

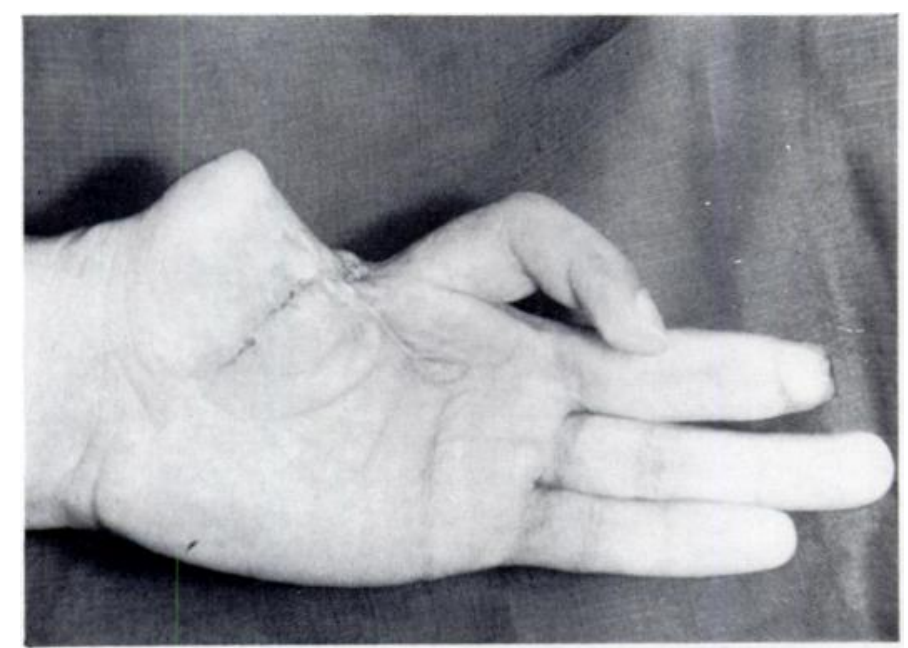

FIG. 41

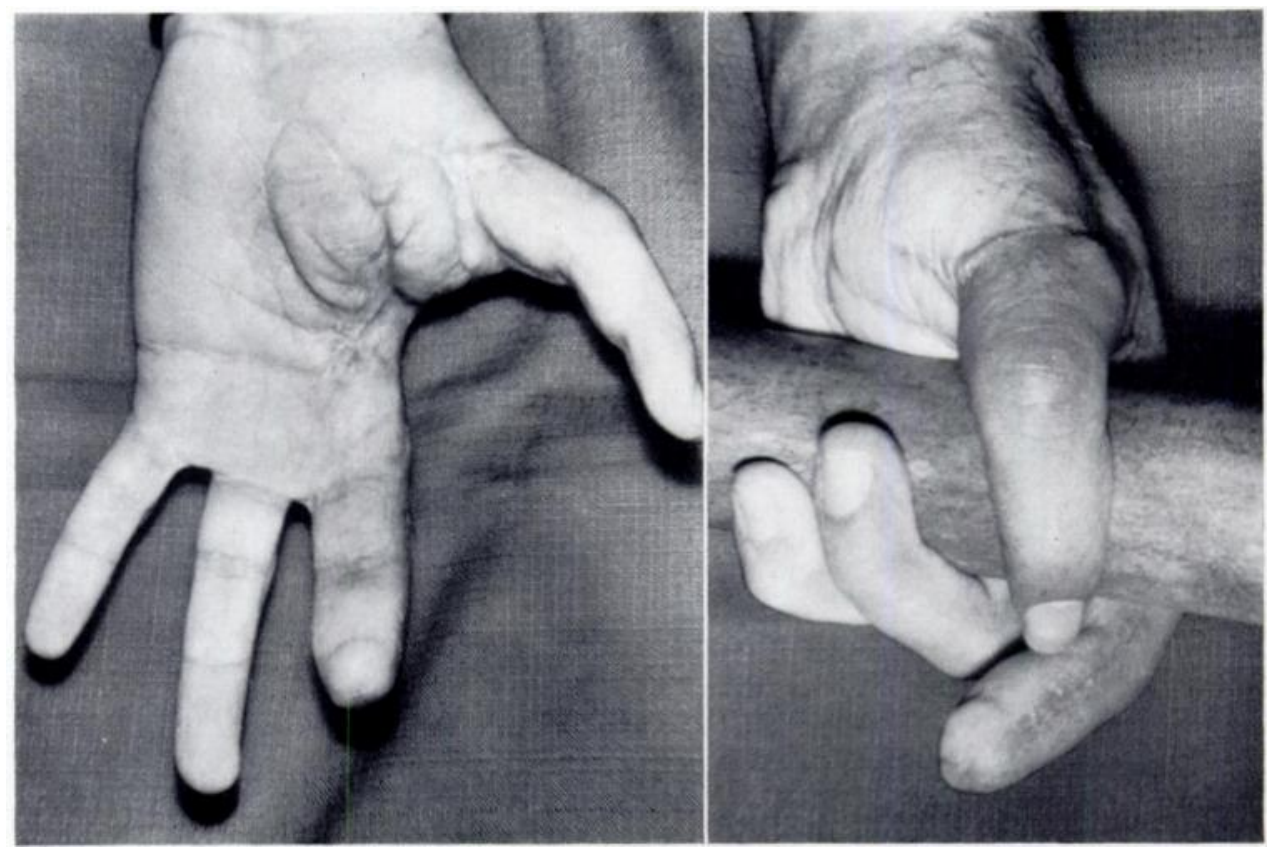

Fig. 42

Pollicisation of functionless index finger. Figure 41 - Before operation. Figure 42-Showing action of the reconstructed thumb.

the general function of the hand. In the more severe example shown in Figures 43 and 44 the thumb and index finger were lost and the middle finger developed a severe flexion deformity. An abdominal tube was used to fill in the thumb cleft at the time of pollicisation. The deformity of the finger was corrected later and the thumb length simultaneously adjusted. 
"There is but one mandatory indication for amputation of a composite hand structure. That indication is loss of blood supply, without the possibility of its restoration." But ". . to retain parts which can neither be restored as useful members, nor can contribute tissues for overall reconstruction is as ridiculous as indiscriminate amputation." (Chase 1964.)

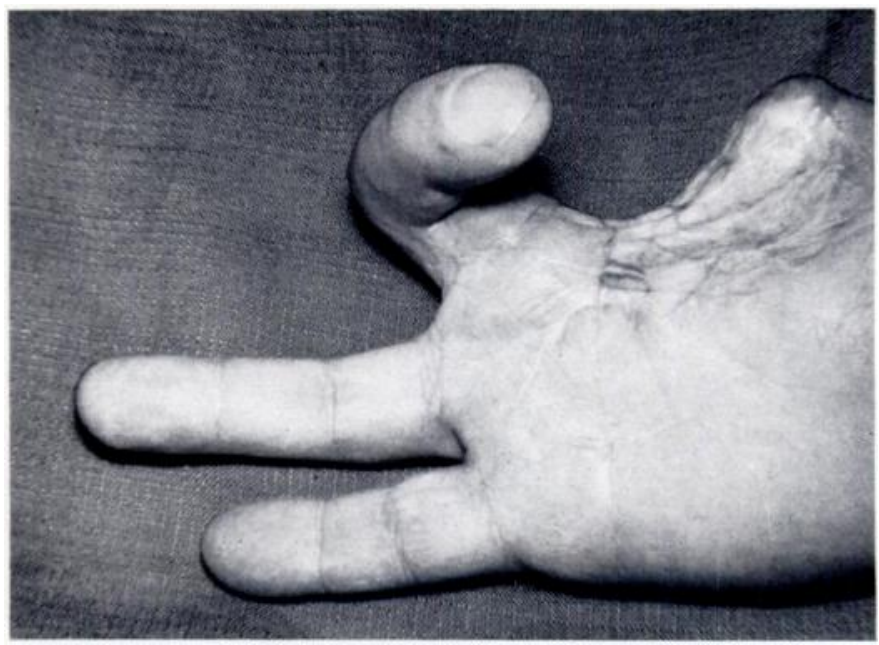

Fig. 43
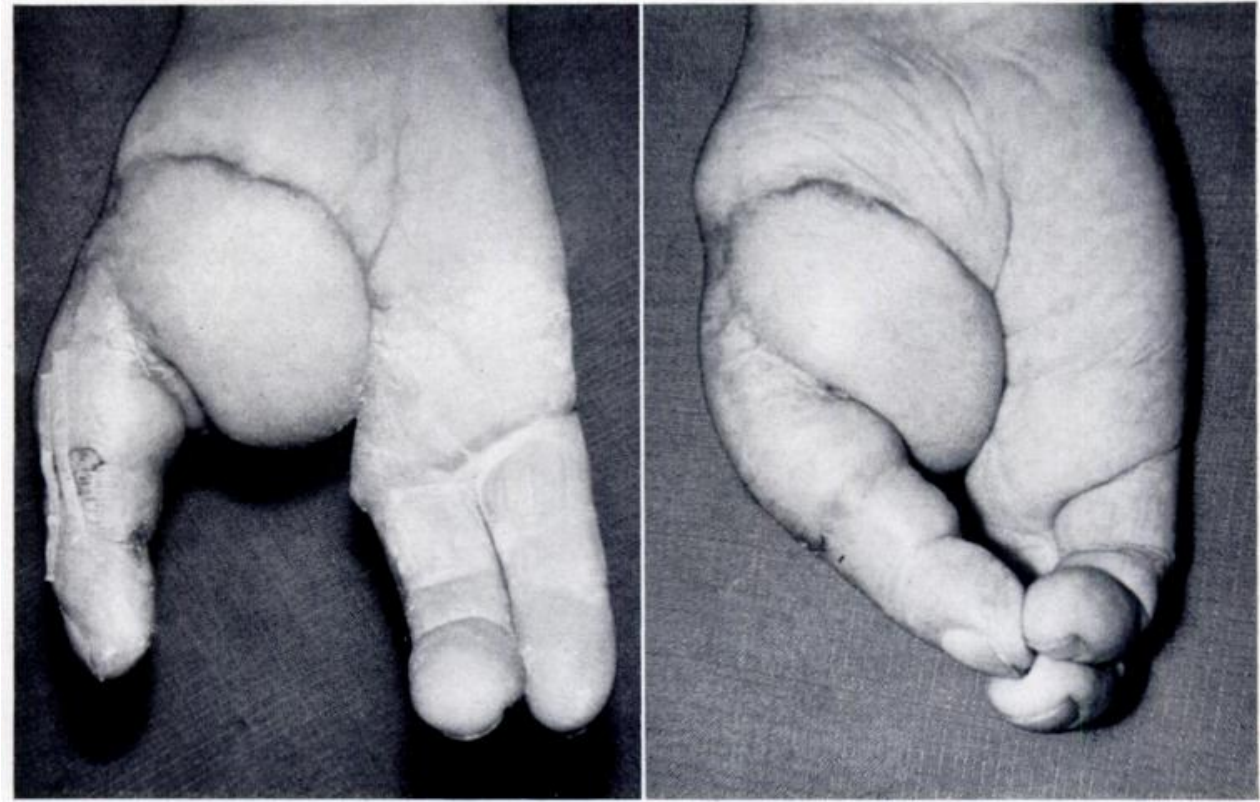

FIG. 44

Pollicisation of functionless middle finger, assisted by abdominal tube flap. Figure $43-$ Before operation. Figure $44-$ Showing action of thumb.

I have discussed some aspects of congenital deformities, Dupuytren s disease, tendon and disruptive injuries of the hand, fully aware that these constitute part only of the whole field of modern hand surgery. The repair of the disabled hand is one of the most fascinating of all surgical tasks-work by the craftsman for the craftsman; for those "who look to their

VOL. 55 B, No. 1, feBruARY 1973 
hands and without whom a city cannot be inhabited". Twenty-five years ago Bunnell (1947) in addressing the American Society for Surgery of the Hand said: "Why are we banded together in this Society? What is the interest that we share? It is in part the search to overcome the difficult, as a chase for the will o' the wisp."

Wisdom is hard to attain and in looking back over the years the thought comes that if one knew then what experience has since taught, there would have been less tears and more rejoicing. The high challenge of the art of surgery demands all that we can give; it is the privilege of the young to select from the past and search out new and better ways for the future.

I would like to thank Mr E. W. O. Adkins for his permission to include the case shown in Figures 36 and 37, Mr B. Wilks and his staff in the Photographic Department of the Derbyshire Royal Infirmary, and Miss Peggy Coupland and Mrs Anne McIntosh for their secretarial assistance.

The following illustrations are reproduced by the courtesy of the publishers: Figure 22, from Operative Surgery (second edition), Butterworth \& Co. Ltd., London; Figures 36 to 40, from Journal of the Royal College of Surgeons of Edinburgh.

\section{REFERENCES}

Albee, F. H. (1919): Orthopedic and Reconstructive Surgery, p. 903. Philadelphia: W. B. Saunders Co. Albee, F. H. (1928): Formation of Radius Congenitally Absent. Annals of Surgery, 87, 105.

Barclay, T. L. (1972): Observations on Skoog's Operation for Dupuytren's Contracture. The Hand, 4, 187. BARDenheuer, B. (1894): Vorstellung von 4 Patienten, an welcher die totale Resektion des ganzen Huftgelenkes ausgeführt worden war. Centralblatt für Chirurgie, 21. Berichte uber die Verhandlungen der Deutschen Gesellschaft für Chirurgie, 23rd Kongress, p. 105.

Bassett, C. A. L., and Carroll, R. E. (1963): Formation of Tendon Sheath by Silicone-rod Implants. Journal of Bone and Joint Surgery, 45-A, 884.

BRUNER, J. M. (1967): The Zig-zag Volar-digital Incision for Flexor-Tendon Surgery. Plastic and Reconstructive Surgery, 40, 571.

Buck-Gramcko, D. (1971): Pollicization of the Index Finger. Journal of Bone and Joint Surgery, 53-A, 1605.

Bunnell, S. (1918): Repair of Tendons in the Fingers and Description of Two New Instruments. Surgery, Gynecology and Obstetrics, 26, 103.

Bunnell, S. (1922): Repair of Tendons in the Fingers. Surgery, Gynecology and Obstetrics, 35, 88.

Bunnell, S. (1947): Hand Surgery. Journal of Bone and Joint Surgery, 29, 824.

Bunnell, S. (1948): Surgery of the Hand. Second edition, p. 627. Philadelphia: J. B. Lippincott Co.

Chase, R. A. (1964): Conservation of Usable Structures in Injured Hands. In Reconstructive Plastic Surgery. Volume 4, The Hand, p. 1579. Edited by J. M. Converse. Philadelphia: W. B. Saunders Co.

Define, D. (1963): New Surgical Treatment of Congenital Absence of the Radius. Sociéte Internationale de Chirurgie Orthopédique et de Traumatologie. Ninth Congress, 653.

Gosset, J. (1949): La pollicisation de l'index. Journal de Chirurgie, 65, 403.

Heikel, H. V. A. (1959): Aplasia and Hypoplasia of the Radius. Acta orthopaedica Scandinavica, Supplement 39.

Hilgenfeldt, O. (1950): Operativer Daumenersatz und Beseitigung von Griefstörungen bei Fingerverlusten. Stuttgart: Ferdinand Enke.

Hoffa, A. (1890): Zur Statistik der Deformitäten. Münchener medicinische Wochenschrift, 37, 237.

Hueston, J. T. (1963): Dupuytren's Contracture, p. 86. Edinburgh: E. \& S. Livingstone.

Hunter, J. M. (1965): Artificial Tendons, Early Development and Application. American Journal of Surgery, $109,325$.

Hunter, J. M., and Salisbury, R. E. (1971): Flexor-tendon Reconstruction in Severely Damaged Hands. Journal of Bone and Joint Surgery, 53-A, 829.

Jones, R., and Lovetr, R. W. (1929): Orthopaedic Surgery. Second edition. New York: William Wood and Co.

Kato, K. (1924): Congenital Absence of the Radius. Journal of Bone and Joint Surgery, 6, 589.

LAMB, D. W. (1972): The Treatment of Radial Club Hand. The Hand, 4, 22.

Littler, J. W. (1953): The Neurovascular Pedicle Method of Digital Transposition for Reconstruction of the Thumb. Plastic and Reconstructive Surgery, 12, 303.

McCash, C. R. (1964): The Open Palm Technique in Dupuytren's Contracture. British Journal of Plastic Surgery, 17, 271.

McIndoe, A., and BeARe, R.L. B.(1958): The Surgical Management of Dupuytren's Contracture. AmericanJournal of Surgery, 95, 197.

MAYer, L., and Ransohoff, N. (1936): Reconstruction of the Digital Tendon Sheath. Journal of Bone and Joint Surgery, 18, 607 . 
Milgram, J. E. (1960): Transplantation of Tendons through Preformed Gliding Channels. Bulletin of the Hospital for Joint Diseases, 21, 250.

Pulvertaft, R. G. (1956): Tendon Grafts for Flexor Tendon Injuries in the Fingers and Thumb. Journal of Bone and Joint Surgery, 38-B, 175.

Pulvertaft, R. G. (1960): The Treatment of Profundus Division by Free Tendon Graft. Journal of Bone and Joint Surgery, 42-A, 1363.

Pulvertaft, R. G. (1972): Delayed Tendon Grafting. In The Hand. Edited by R. Tubiana. Philadelphia: W. B. Saunders Co. (In preparation.)

Robson, A. W. M. (1889): A Case of Tendon-grafting. Transactions of the Clinical Society of London, 22, 289.

Romano, C. (1894): Grave mano torto congenita. Archivio di ortopedia, 11, 80.

RYERSON, E. W. (1924): Quoted by Kato, R. (1924).

SAYre, R. H. (1894): A Contribution to the Study of Club-Hand. Transactions of the American Orthopedic Association, 6, 208.

Skoog, T. (1967): The Transverse Elements of the Palmar Aponeurosis in Dupuytren's Contracture. Scandinavian Journal of Plastic and Reconstructive Surgery, $1,51$.

Stark, D. E. (1945): Congenital Absence of the Radius. Journal of Bone and Joint Surgery, $27,572$.

SWANSON, A. B. (1957): Personal communication.

Verdan, C. E. (1972): Half a Century of Flexor-tendon Surgery. Journal of Bone and Joint Surgery, 54-A, 472.

Watson-Jones, R. (1943): Fractures and Joint Injuries. Third edition, Volume 2, p. 597. Edinburgh: E. \& S. Livingstone.

VOL. 55 B, NO. 1, FEBRUARY 1973 